\title{
The Effect of Team-Based Learning in a Neurorehabilitation Course within a Physical Therapy Assistant Academic Program
}

\author{
Laurie A. Schroder \\ University of St. Augustine for Health Sciences
}

DOI: https://doi.org/10.46409/sr.LCFM1759

Follow this and additional works at: https://soar.usa.edu/dissertations

Part of the Vocational Education Commons

\section{Recommended Citation}

Schroder, L. A. (2017). The Effect of Team-Based Learning in a Neurorehabilitation Course within a Physical Therapy Assistant Academic Program. [Doctoral project, University of St Augustine for Health Sciences]. SOAR @ USA: Student Dissertations Collection. https://doi.org/10.46409/sr.LCFM1759 
Running Head: THE EFFECT OF TEAM-BASED LEARNING

\title{
THE EFFECT OF TEAM-BASED LEARNING IN A NEUROREHABILITATION COURSE WITHIN A PHYSICAL THERAPIST ASSISTANT ACADEMIC PROGRAM \\ Laurie A. Schroder
}

\begin{abstract}
A Dissertation Presented in Partial Fulfillment
Of the Requirements for the Degree

Doctor of Education
\end{abstract}

University of Saint Augustine

Month, Year 
(C) Laurie Schroder, 2017 


\title{
THE EFFECT OF TEAM-BASED LEARNING IN A NEUROREHABILITATION COURSE WITHIN A PHYSICAL THERAPIST ASSISTANT ACADEMIC PROGRAM
}

by

\author{
Laurie A. Schroder \\ has been approved \\ Month, Year
}

APPROVED:

\author{
LORI KUPCZYNSKI, EdD, Faculty Mentor and Chair \\ CHERYL PETERS-BRINKERHOFF, EdD, Committee Member \\ CINDY MATHENA, PhD, Committee Member
}

ACCEPTED AND SIGNED:

LORI KUPCZYNSKI, EdD 
Abstract 
Acknowledgements 


\section{Table of Contents}

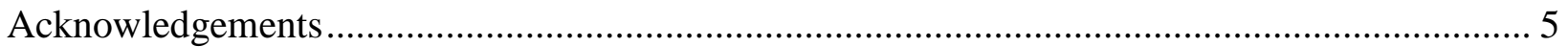

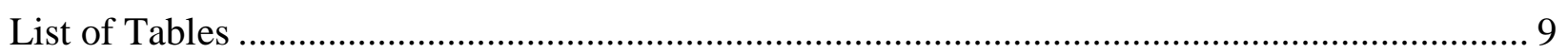

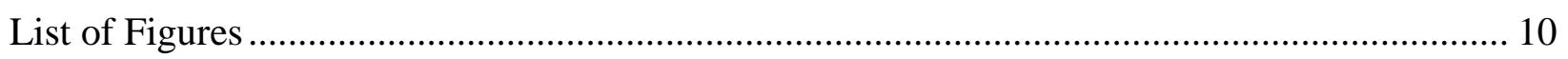

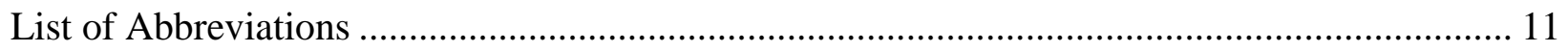

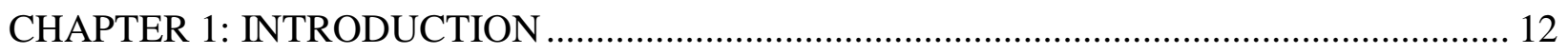

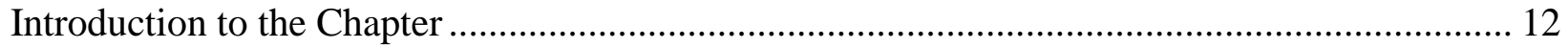

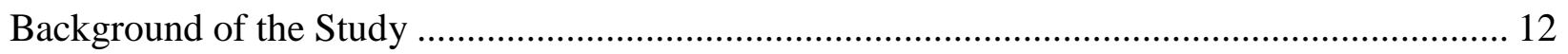

Statement of the Problem.................................................................................................. 16

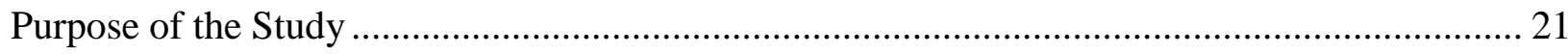

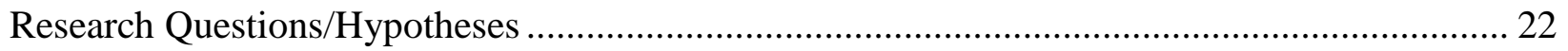

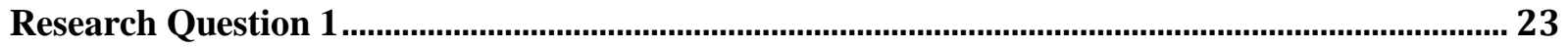

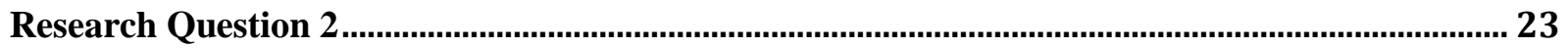

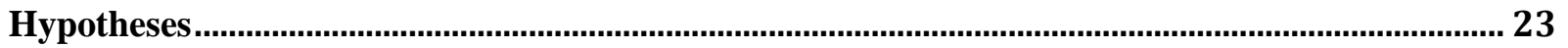

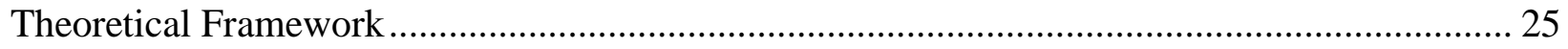

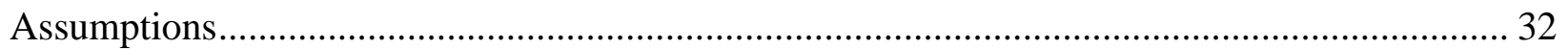

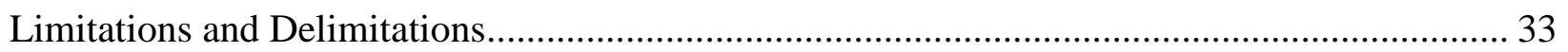

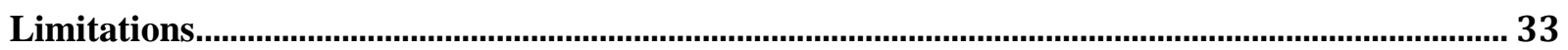

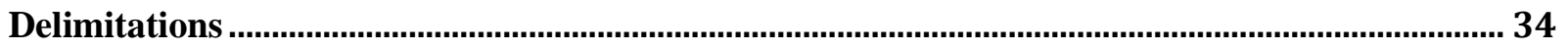

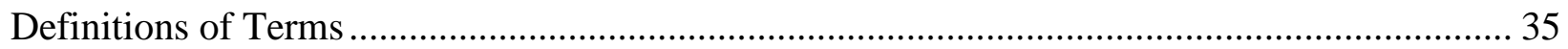

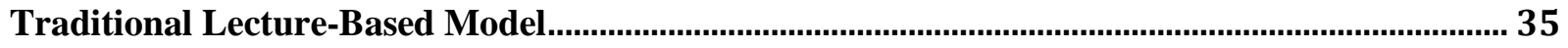

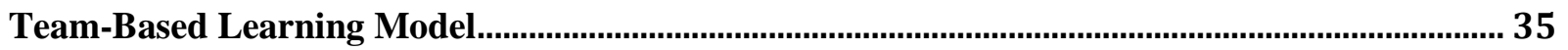

Chapter Summary and Organization of the Remainder of the Study ...................................... 37

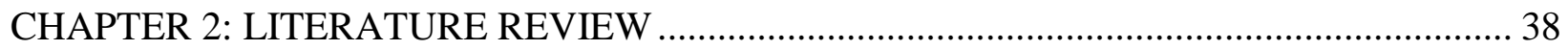

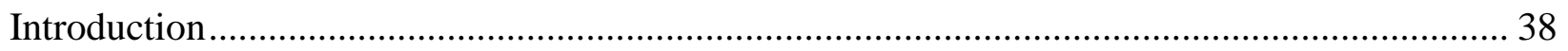

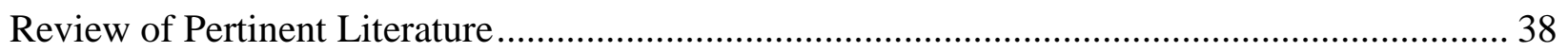

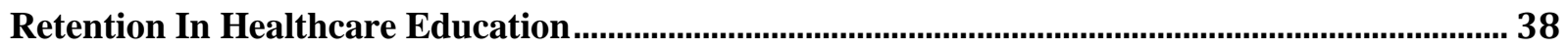

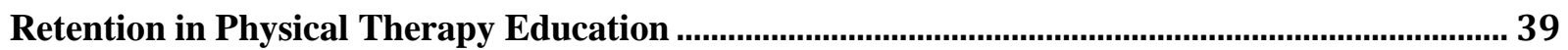

Theoretical Framework That Supports the Selection of Team-Based Learning as an Instructional

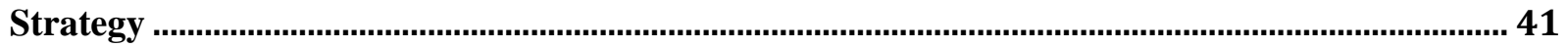

Active Learning Strategies vs. Passive Learning Strategies for Improved Outcomes in Healthcare

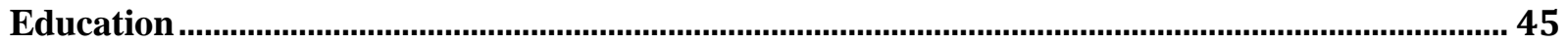

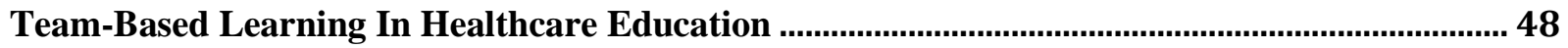

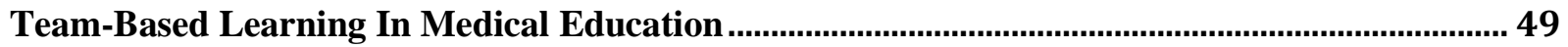

Team-Based Learning in Nursing and Pharmacy Education ........................................................... 50

Team-Based Learning in Physical Therapy Education ........................................................................ 51

The Structure of Team-Based Learning .......................................................................... 51

Conceptual Model for Scholarly Work on TBL in Health Professions Education ......................... 61 


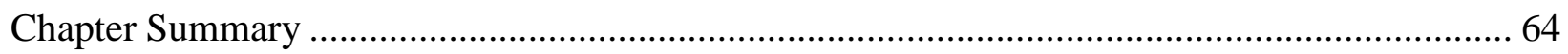

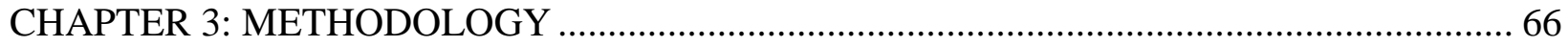

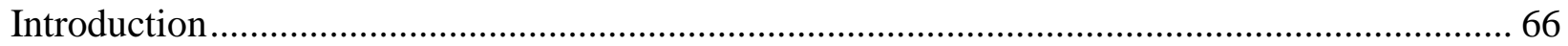

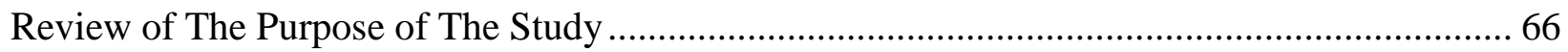

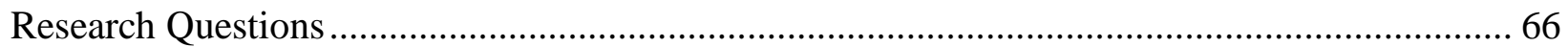

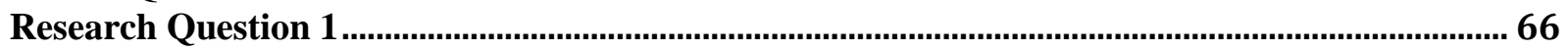

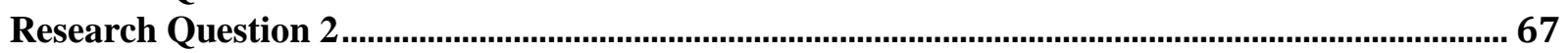

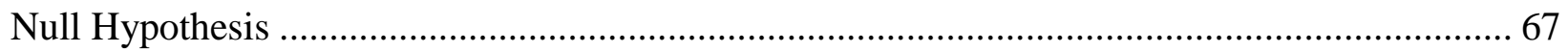

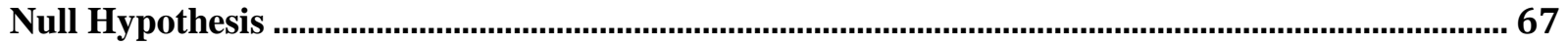

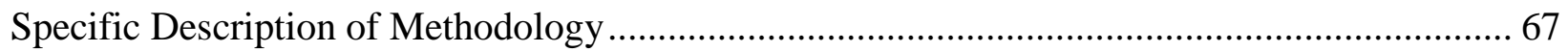

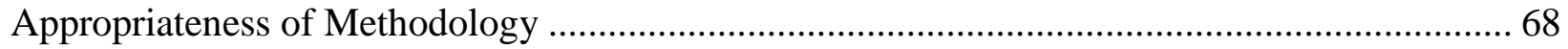

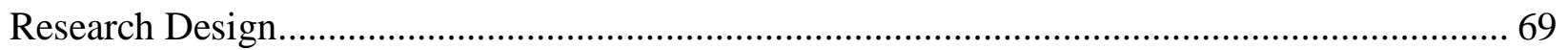

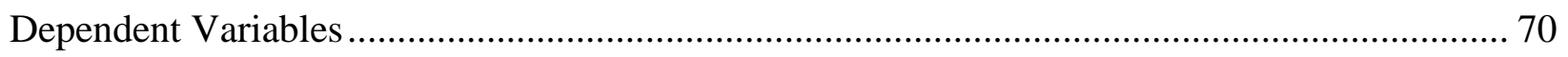

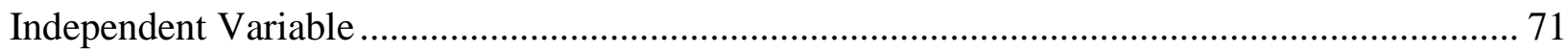

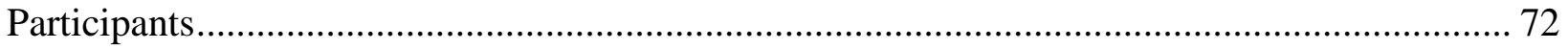

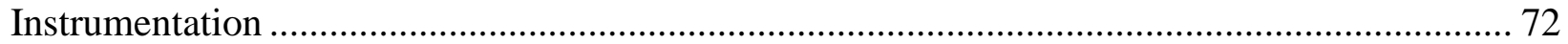

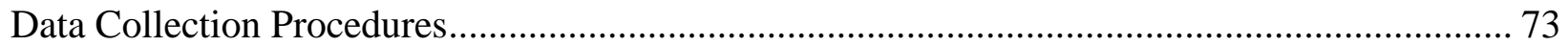

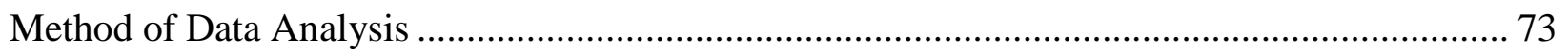

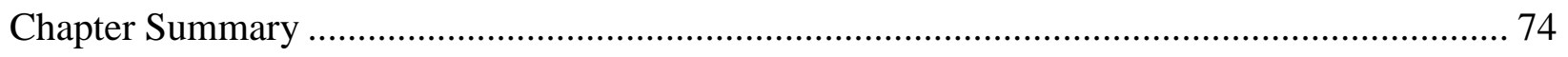

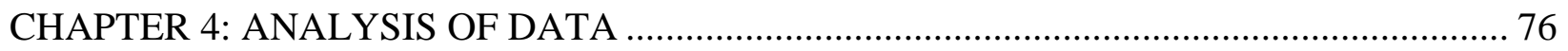

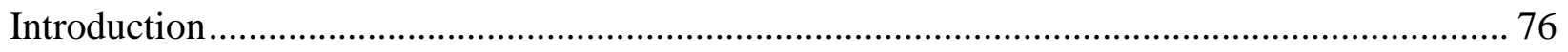

Explanation of Methodology and Overview of Results...................................................... 76

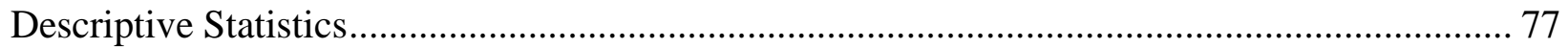

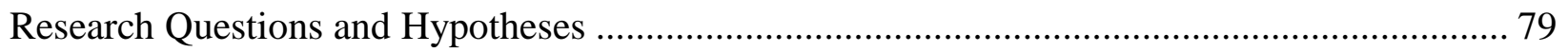

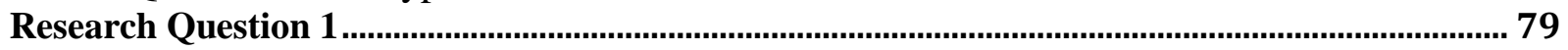

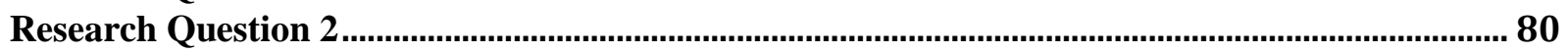

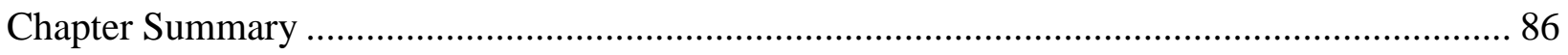

CHAPTER 5: SUMMARY, CONCLUSIONS, AND RECOMMENDATIONS ..................... 88

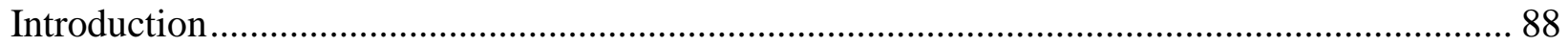

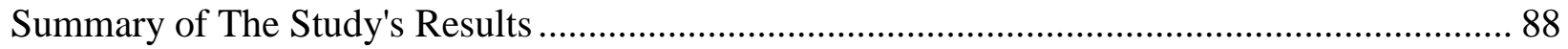

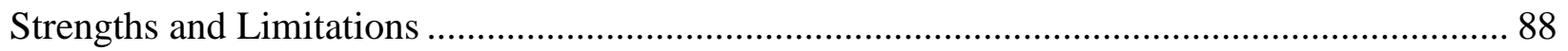

Recommendations for Future Research ...................................................................... 88

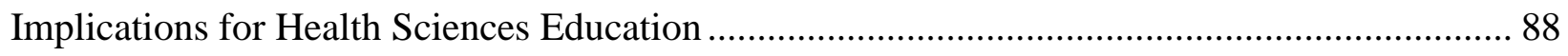

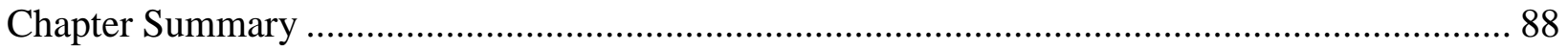




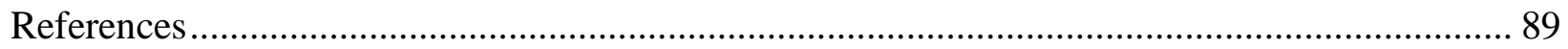

APPENDIX A: Sample Pre-Course Reading Guide.............................................................. 102

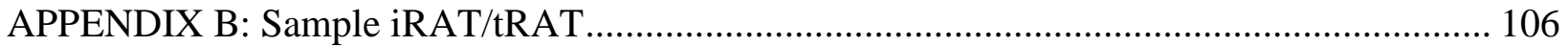

APPENDIX C: Sample Basic Application Task (BAT) ………………………………........... 108 


\section{List of Tables}

Tables

Page

1. Percentages and Frequencies, Study Variables................... 76

2. Means and Standard Deviations, Scale Variables................ 77

3. Descriptive Statistics for Exam 1 Score by Instructional Method. 77

4. Descriptive Statistics for Exam 2 Score by Instructional Method. $\quad 78$

5. Descriptive Statistics for Exam 3 Score by Instructional Method. 78

6. Descriptive Statistics for Exam 4 Score by Instructional Method. $\quad 78$

7. Analysis of Covariance (ANCOVA) Results for Exam 1........ 80

8. Analysis of Covariance (ANCOVA) Results for Exam 2........ 82

9. Analysis of Covariance (ANCOVA) Results for Exam 3........ 83

10. Analysis of Covariance (ANCOVA) Results for Exam 4........ 84 
Figures

\section{List of Figures}

1. Team-based Learning Instructional Activity Sequence........... 55

2. Immediate Feedback Assessment Technique................... 57

3. TBL Implementation Steps............................. 59

4. Haidet's Framework for Reporting TBL Research.............. 62

5. Adapted Framework for Reporting TBL Research............... 62 


\section{List of Abbreviations}

Abbreviation

BAT

CAPTE

FSBPT

NPTE-PTA

PBL

PTA

RAP

RAT

TBL

\section{Explanation}

Basic Application Task

Commission on Accreditation in Physical

Therapy Education

Federation of State Boards of Physical Therapy

National Physical Therapy Examination -

Physical Therapist Assistant

Problem-based Learning

Physical Therapist Assistant

Readiness Assurance Process

Readiness Assurance Test

Team-based Learning 


\section{CHAPTER 1: INTRODUCTION}

\section{Introduction to the Chapter}

The purpose of this chapter is to provide the incentive and reasoning for conducting a research study focusing on the use of the team-based learning (TBL) method with physical therapist assistant students. The background for the study is presented, and the significance of this study, which uses a relatively new instructional method with a high functioning group of students who have proved academic success, is provided. Research questions and hypotheses are presented following a discussion of the study's purpose, and the theoretical framework for cooperative and collaborative active learning is outlined. Finally, the assumptions, limitations and delimitations that guided the study are reviewed.

\section{Background of the Study}

Active learning has been found to be more successful in producing self-regulation in students than traditional, lecture-focused instruction. Sungur and Tekkaya (2006) found, when comparing two large groups of students who either received traditional lecture instruction or who engaged in problem-based learning (PBL), PBL students had higher levels of intrinsic goal orientation, task value, use of learning strategies, critical thinking, metacognitive self-regulation, effort regulation, and peer learning. This was supported by Sangestani and Khatiban (2013), who found that the addition of PBL to traditional lecture improved application of theory in clinical practice, increased learning motivation, and enhanced activity in class. PBL and other cooperative and collaborative active learning has also been found to increase academic achievement; improve students' attitudes towards each other; increase self-esteem, self-direction, and role taking abilities; improve students' sense of responsibility for their own learning and 
teach students the skills necessary for life-long learning (Griffith, 1990). These same benefits may not be developed in a lecture-based course.

Active learning is more likely to fulfill the principles outlined by Chickering \& Gamson (1987) as it allows students the opportunity to actively construct learning through experience, both individually and socially. Lecture, which enables an expert to deliver information to groups of any size, is by its nature less likely to involve direct student-faculty contact (Jones, 2010, as cited in Mennenga, 2010). Lecture also does not encourage cooperation among students, nor does it encourage active learning. It is, in fact, notably passive (H. A. Mennenga, 2013). In contrast, active learning, when well constructed, not only meets these principles, but also allows for prompt and specific feedback, emphasizes time on task, communicates high expectations, and respects diverse talents and ways of learning (Chickering \& Gamson, 1987). Collaborative and cooperative learning are two related, but different, strategies that have proven effective in teaching difficult material (Breneiser, Monetti, \& Adams, 2012; Davidson, Howell Major, \& Michaelson, 2014; Johnson, Johnson, \& Smith, 2014). Cheong (2010) defines cooperative learning as an instructional method inclusive of several key elements. These key elements include positive interdependence, accountability, team formation, size, cognitive development, and social development (Cheong, 2010). Cooperative learning, as compared to collaborative learning, is far more structured and prescriptive. Collaborative learning tends to be informal, and is designed to meet students on the level at which they are currently performing (Oxford, 1997) as well as increase knowledge and skill level from students' starting level toward some learning goal or objective. Collaborative learning is based on the principles of Vygotskianism, including the zone of proximal development, and scaffolding (Vygotsky, 1987). Both teaching strategies have the additional advantage over lecture of developing students' communication, teamwork, 
and critical thinking skills. Additively, Chung and Jackson Behan (2010) found group learning associated with collaborative learning activities motivated students (Chung \& Jackson Behan, 2010; Lunstroth, 2014; Vanderzalm, Hall, McFarlane, Rutherford, \& Patterson, 2013).

Team-based learning (TBL), created by Larry Michaelsen and further developed by Larry Michaelsen and Michael Sweet (2004), for use in large business classes, is a form of active learning that includes elements of both collaborative and cooperative learning. Since its inception, TBL has been integrated into medical, pharmaceutical, and social sciences higher education, as well as into K-12 classrooms (Haidet, Kubitz, \& McCormack, 2014). TBL relies heavily on small group interaction, and is focused on providing students with opportunities to cooperatively practice applying concepts. Students put into practice approaching and solving real world problems after being exposed to relevant course content (Michaelsen \& Sweet, 2008, 2011). Team assignment and development are critical to the success of TBL. Strategically forming permanent teams is the first of four foundational practices of TBL. The other three foundational practices, as outlined by Michaelsen (2004) are: ensuring student familiarity with course content by utilizing a Readiness Assurance Process; developing students' critical thinking skills by using carefully designed in-class activities and assignments; and creating and administering a peer assessment and feedback system (Michaelsen, Bauman Knight, \& Fink, 2004; Michaelsen, Davidson, \& Howell Major, 2014; Michaelsen \& Sweet, 2008, 2011).

Typically, a TBL course is divided into five to seven topic-based learning units administered over the course of an academic term (Michaelsen et al., 2004; Michaelsen \& Sweet, 2008, 2011). Each unit begins with pre-class, individually completed assignments that are designed to familiarize students with the key concepts for each unit. These pre-class assignments might include reading guides, videos and other media, or practice work. The first 
in-class activity for each unit is a Readiness Assurance Process (RAP), which is designed to assess student understanding of the pre-class assignment. The RAP consists of both individual and team Readiness Assurance Tests (RATs) and is followed by an instructor clarification review based on misperceptions that may have come to light through the RAT process. The remainder of the unit requires students to use what they have learned in team application exercises, which are referred to as basic application tasks (BATs) (Michaelsen \& Sweet, 2008). Examinations, generally in multiple-choice format, are given periodically throughout the course. TBL has been shown to increase student engagement through accountability, active and cooperative learning, and the development of a skill set that leads to improved student ability to make and judge decisions (Michaelsen, Parmelee, McMahon, \& Levine, 2008). In the text edited by Haidet, Schneider, and Onady (2008), Parmelee lists the additional benefits of teambased learning:

1. It is suitable for large classes held in lecture halls;

2. It engages students fully during class time;

3. Students come to class on time and they come prepared;

4. One faculty member can conduct an entire session;

5. Several professional competencies can be addressed (communication, interpersonal skills, teamwork skills, including giving and receiving peer feedback, knowledge acquisition, and applying knowledge to real case problems);

6. Academic achievement on end-of-course examinations is the same or better than with traditional lecture format;

7. It offers students opportunities to develop clinical reasoning skills in the context of a supportive and engaged group of peers; 
8. It contributes to the development of a learning community for a class. (p. 7)

\section{Statement of the Problem}

Physical therapist assistant (PTA) education is a rigorous process that occurs over a twoyear period and results in the graduation and licensure of entry-level generalist practitioners who work under the supervision of physical therapists. Although the majority of PTA programs utilize selection criteria in an attempt to secure capable students, graduation rates range from 41.7\% - 100\% for all programs accredited by the Commission on Accreditation in Physical Therapy Education (CAPTE). The average graduation rate is $81 \%$ (American Physical Therapy Association, 2015a). Attrition from PTA programs is primarily due to academic issues (Desmarais, Woble-Valenski, \& Oestmann, 2011).

The curriculum that must be mastered over the course of a physical therapist assistant education program is inclusive of fifty-one interventions, tests or measures dictated by the Standards and Required Elements for Accreditation of Physical Therapist Assistant Education Programs (Commission on Accreditation in Physical Therapy Education, 2016). Training in these skills is founded on courses in general education that include written communication and biological, physical, behavioral and social sciences. The length of a PTA program is typically two years, and consists of general education, technical coursework, and clinical education. The American Physical Therapy Association states, "primary physical therapy content areas in the curriculum may include, but are not limited to, anatomy and physiology, exercise physiology, biomechanics, kinesiology, neuroscience, clinical pathology, behavioral sciences, communication, and ethics/values" (American Physical Therapy Association, 2015b).

Among courses required in medical and allied health education, including PTA education, those related to the neurosciences are some of the most difficult (Anwar, Shaikh, 
Sajid, Cahusac, Alarifi, \& Al Shedoukhy, 2015). The fear that students feel when approaching neurological courses has been labeled "neurophobia," and has been demonstrated to continue into practice (Anwar et al., 2015; Maslakpak, Parizad, \& Zareie, 2015).

Flanagan, Walsh, and Tubridy (2007) suggested that the difficulties that medical students and doctors have in dealing with patients with neurological problems is due to perceptions that neurology is difficult, merely diagnostic, and that teaching of the subject is not done well. Delivered by lecture methods, difficult material is likely to be lost quickly, and students can develop anxiety, dislike, and eventual disinterest in the subject, and, according to MaranhaoFilho (2014) "a lack of student integration of basic science and clinical information into a cohesive whole" (p. 743). Without deeper learning of neurological principles, students are unlikely to recall and apply those principles in clinical practice after graduating (Flanagan et al., 2007). A survey of medical students and doctors indicated that they felt their knowledge in neurology was limited, their confidence in assessing patients with neurological problems was lowest of all specialties, and they had received insufficient neurological teaching and limited exposure to neurological patients (Flanagan et al., 2007; Zinchuk, Flanagan, Tubridy, Miller, \& McCullough, 2010). Medical students and junior physicians report difficulty in identifying and managing patients with neurological problems, which is generally attributed to explanations ranging from sense of intimidation by the complexity of neurosciences to the "poor teaching" experienced during preclinical and clinical years (Lukas, Cooper, Morgan, Brorson, Dong, \& Sherer, 2014; Zinchuk et al., 2010). Relatively few medical students choose to pursue graduate residency in neurology. Humbert and Chang (2014) attributed this specialty-specific fear as a consequence of the inherent difficulty of neuroanatomy, insufficient teaching that bridges science and practice, diagnostic complexity, and a perceived lack of sufficient exposure. 
Youssef (2009) reported that medical students who identified neurology as the subject they found most difficult and had least knowledge of suggested that greater clinical and practical exposure, more time spent on the subject, and improved teaching skills were needed to improve teaching of neurology. Multiple changes have been made to medical training in neurology in the past decade (Humbert \& Chang, 2014; Maranhao-Filho, 2014; McColgan, McKeown, Selai, Doherty-Allan, \& McCarron, 2013). Many medical schools are integrating the neurological sciences into interdisciplinary courses, and methods of instruction are changing from lecturebased to small-group, problem-based learning formats (Galetta, Jozefowicz, \& Avitzur, 2006). The Academy of Neurological Physical Therapy has made recommendations for similar curricular changes in physical therapy education (Academy of Neurologic Physical Therapy, 2015).

According to Maslakpak et al. (2015), when a great deal of material is delivered via lecture format, students tend to disengage from the material and resort to rote memorization. Additionally, lecture alone tends to limit students' participation and engagement with material, resulting in poor student concentration, which reduces students' absorption of information, stability and recalling of topics. Traditional, passive, lecture-based learning often leads to unsatisfactory learning outcomes due to limited student interaction, and a lack of motivation to engage in deeper, self-regulated study (Maslakpak et al., 2015; Yang, Jiang, Xu, Liu, \& Liang, 2014). Neurorehabilitation principles necessitate teaching through a more engaging approach (McColgan et al., 2013) as these principles are essential to the successful treatment of patients and clients for physical therapist assistants as they are to members of other healthcare fields (Rathner \& Byrne, 2014). 
Active learning, defined as "activities introduced into traditional lecture that promote student engagement” (Prince, 2004, p. 1), can improve recall of information and student engagement with material. Hake (1998) examined data for over 6,000 introductory physics students in an effort to identify the efficacy of active learning to improve student engagement and success in a difficult subject. Test scores measuring conceptual understanding were approximately twice as high in classes using active learning than in traditional, lecture-based courses (Prince, 2004).

Lecture-based instruction, as well as curricular designs encompassing active learning, are used in physical therapy education. Active learning models include problem-based learning (PBL), flipped classroom models, skill laboratories and simulation, and demonstration. Of these, lecture based, demonstration, and problem-based learning remain the most popular; with problem-based learning being the most frequently used active learning strategy (Zaidi \& Nasir, 2014). Many of the strengths of problem-based learning reside in its cooperative and collaborative structure, wherein students work together to generate solutions to a given problem, generate hypotheses, discover new knowledge, debate and discuss, and arrive at decisions that solve the problem. However, PBL is extremely resource intensive, requiring one facilitator for every group of ten students (Burgess, Ayton, \& Mellis, 2016). Team-based learning (TBL), a cooperative and collaborative instructional strategy developed by Larry Michaelsen, incorporates the strengths of PBL while mediating its challenges (Michaelsen et al., 2004). Differences between PBL and TBL stem primarily from the development of effective and self-managed teams, the development of which is critical for TBL. A key element of the teacher's role in TBL is to create effective teams. Once these teams are created, one teacher can easily manage a large classroom (Michaelsen et al., 2014). 
Studies regarding the use of TBL have been completed in many different course types; however, studies related to material taught in physical therapy have been limited to gross anatomy (Livingston, Lundy, \& Harrington, 2014). Tan, et al. (2011) completed a study that aimed to determine if TBL was more effective than passive learning in improving outcomes in two key neurology topics for medical students - neurological localization and neurological emergencies - but the use of TBL for teaching neurological topics to physical therapist, or physical therapist assistant, students has not been studied (Tan, Kandiah, Chan, Umapathi, Lee, \& Tan, 2011).

Moreover, establishing the efficacy of TBL has been difficult because of the various designs that have been used when comparing TBL to other instructional methods. For example, most studies have used one or two units within a course as a comparator to traditional instructional methods, versus the use of a complete TBL course compared to a complete course delivered utilizing traditional methods (Altintas, Altintas, \& Caglar, 2014). In other studies, random assignment of students to a TBL or traditional methods' course has only been used in a few studies (Koles, Nelson, Stolfi, Parmelee, \& Destephen, 2005; Thomas \& Bowen, 2011). Researchers have also used outcomes measured that may not correlate directly to achievement of student outcomes. Outcomes measured have typically included student satisfaction, faculty satisfaction and student engagement (Currey, Oldland, Considine, Glanville, \& Story, 2015; Ku, Tseng, \& Akarasriworn, 2013; Livingston et al., 2014; Roh, Lee, \& Mennenga, 2014). Less often, outcomes include examination scores. In the study by Tan et al. (2011) data was collected beyond the end of the course in an attempt to evaluate student retention of important content (Cheng, Liou, Tsai, \& Chang, 2014; Maslakpak et al., 2015; H. A. Mennenga, 2013; Tan et al., 2011). 
Following a systematic review of available TBL literature, Sisk (2011) concluded that, "despite limitations of the studies focusing on examination scores, results have demonstrated that TBL is a promising instructional method. Further research using consistent measurements of student learning would confirm whether TBL should be more widely used" (p.668). Generalizability of current studies of TBL is also limited by the studies' lack of control groups, modifications in TBL design and/or delivery, and the use of group assignment that allowed for exposure of different groups to different levels of previous learning. For example, Bleske, Remington, Wells, Dorsch, Guthrie, Stumpf, Alaniz, Ellingrod, and Tingen (2014) compared examination performance between second-year and third-year pharmacy students, a study design that allowed for comparison of knowledge demonstration on the same content, but with different levels of prior knowledge.

\section{Purpose of the Study}

The purpose of this quantitative, quasi-experimental, ex post facto cohort study was to compare the effectiveness of team-based learning (TBL) with traditional teacher-led, lecturebased learning, on learning outcomes in neurorehabilitation. This study was completed with second-year physical therapist assistant students enrolled in a two-year physical therapist assistant program in a small, proprietary college in Middle Tennessee. The study measured learning outcomes during the course, as evidenced by in-course examination scores, and learning outcomes in neuroscience overall as evidenced by scores on the neurological concepts' sections of the National Physical Therapist Assistant Examination (NPTE-PTA) taken by students following graduation.

Previous research of the application of TBL has focused primarily on student satisfaction with the TBL process, faculty satisfaction, and student demonstrated course learning outcomes 
immediately following a unit delivered by TBL or course completion. These authors have shown an increased level of student engagement as well as student and faculty satisfaction (Altintas et al., 2014; Burgess et al., 2016; Clark, Nguyen, Bray, \& Levine, 2008; Currey et al., 2015; Haidet et al., 2014; H. Mennenga, 2010; H. A. Mennenga, 2013; Roh et al., 2014; Sisk, 2011). However, student and faculty satisfaction are not necessarily indicative of improved student learning outcomes.

Of those studies that have been done to assess TBL as a course-long strategy and its effect on learning outcomes, researchers have found mixed results (Fatmi, Hartling, Hillier, Campbell, \& Oswald, 2013; Haidet et al., 2014; Sisk, 2011). This may be due in part to modifications made to the TBL process, differences between study groups, and faculty comfort with TBL, in addition to other factors. Most studies compared immediate outcomes only, via the assessment of data produced by course examinations (Bleske et al., 2014; Fatmi et al., 2013; Maslakpak et al., 2015). Only one author assessed retention of key material, through data collected 48 hours after class conclusion (Burgess, McGregor, \& Mellis, 2014; McColgan et al., 2013; Sisk, 2011; Tan et al., 2011).

This study made a comparison between the learning outcomes by two relatively homogenous groups of students, utilizing the same or, in the case of the National Physical Therapy Examination - Physical Therapist Assistant version, comparable assessment tools. One group of students was taught using a lecture-based method, and one group was taught using TBL, exactly as outlined by Michaelsen and Sweet (2008).

\section{Research Questions/Hypotheses}

The study is guided by the following research questions: 


\section{Research Question 1}

Is there a significant difference in achievement of student learning outcomes as measured by in-class examination scores on four class examinations between second-year physical therapist assistant students who participated in traditional teacher-led, lecture-based learning and second-year physical therapist assistant students who participated in TBL in a second year neurorehabilitation course while controlling for student GPA at the beginning of the course, in a two-year integrated physical therapist assistant program based in a small proprietary college in Middle Tennessee?

\section{Research Question 2}

Is there a significant difference in achievement of student learning outcomes as measured by the National Physical Therapy Examination - Physical Therapist Assistant version, between second-year physical therapist assistant students who participated in traditional teacher-led, lecture-based learning and second-year physical therapist assistant students who participated in TBL in a second year neurorehabilitation course in a two-year integrated physical therapist assistant program based in a small proprietary college in Middle Tennessee?

\section{Hypotheses}

In this study, the researcher hypothesized that students who participate in the Neurological Rehabilitation course delivered using a team-based learning course design will be more engaged in and interested in the material presented, and that the team structure of TBL will serve to motivate students to improve independent study and preparation behaviors that will ultimately result in higher learning outcomes.

Hypothesis 1. There is a significant difference in achievement of student learning outcomes as measured by in-class examination scores on Exam 1 between second-year physical 
therapist assistant students who participated in traditional teacher-led, lecture-based learning and second-year physical therapist assistant students who participated in TBL in a second year neurorehabilitation course, while controlling for student GPA at the beginning of the course, in a two-year integrated physical therapist assistant program based in a small proprietary college in Middle Tennessee.

Hypothesis 2. There is a significant difference in achievement of student learning outcomes as measured by in-class examination scores on Exam 2 between second-year physical therapist assistant students who participated in traditional teacher-led, lecture-based learning and second-year physical therapist assistant students who participated in TBL in a second year neurorehabilitation course, while controlling for student GPA at the beginning of the course, in a two-year integrated physical therapist assistant program based in a small proprietary college in Middle Tennessee.

Hypothesis 3. There is a significant difference in achievement of student learning outcomes as measured by in-class examination scores on Exam 3 between second-year physical therapist assistant students who participated in traditional teacher-led, lecture-based learning and second-year physical therapist assistant students who participated in TBL in a second year neurorehabilitation course, while controlling for student GPA at the beginning of the course, in a two-year integrated physical therapist assistant program based in a small proprietary college in Middle Tennessee.

Hypothesis 4. There is a significant difference in achievement of student learning outcomes as measured by in-class examination scores on Exam 4 between second-year physical therapist assistant students who participated in traditional teacher-led, lecture-based learning and second-year physical therapist assistant students who participated in TBL in a second year 
neurorehabilitation course, while controlling for student GPA at the beginning of the course, in a two-year integrated physical therapist assistant program based in a small proprietary college in Middle Tennessee.

Hypothesis 5. There is a significant difference in achievement of student learning outcomes as measured by NPTE-PTA Neuromuscular and Nervous System scores between second-year physical therapist assistant students who participated in traditional teacher-led, lecture-based learning and second-year physical therapist assistant students who participated in TBL in a second year neurorehabilitation course, while controlling for student GPA at graduation, age, gender, and race, in a two-year integrated physical therapist assistant program based in a small proprietary college in Middle Tennessee.

\section{Theoretical Framework}

The theoretical framework for this study is presented below. The framework is a blend of the learning theories of constructivist learning theorists, and is grounded in the belief that cooperative, social learning environments that encourage the development of self-efficacy and self-regulated learning lead to improved learning (Bandura, 1986, 2005; Schunk \& Zimmerman, 1997; Vygotsky, 1987; Zimmerman, 1990).

A traditional, lecture-based didactic model is designed to transfer information from the teacher-as-expert to the student. This model is focused on the teacher's delivery and the course content (Hrynchak \& Batty, 2012). The role of the student is to memorize and restate facts rather than to work at the level of application, which requires an understanding of the material (Michaelsen et al., 2008). Team-based learning (TBL) is a dialectic teaching method grounded in the constructivist educational theory. The main elements of constructivist theory include the role of the teacher as a facilitator to learning, the opportunity to expose inconsistencies between 
learners' current understanding and new knowledge or experiences, active learning using relevant, real-world problems and group interaction, and time for reflection and adaptation to new information (Hrynchak \& Batty, 2012).

The qualities of team-based learning can be summarized by the principles outlined by Chickering and Gamson (1987). These authors delineated seven principles for good practice in undergraduate education. All seven are reflective of constructivist educational theory.

Chickering and Gamson's (1987) seven principles are easily identified in team-based learning:

\begin{tabular}{l} 
Good Practice Element \\
\hline Encourages contact between students and \\
faculty \\
Develops reciprocity and cooperation among \\
students
\end{tabular}

Encourages active learning

Gives prompt feedback

Emphasizes time on task

Communicates high expectations

Respects diverse talents and ways of learning
Team-based Learning Component

Assignment to permanent teams; teams interact independently and with faculty facilitation

Students achieve independently and as a team; teams work together to solve real-world problems; teams present and defend their conclusions together

Students engage in teamwork to solve complex, real-world problems

The iRAT and tRAT processes give prompt feedback regarding knowledge and understanding level; teacher mini-lecture following tRAT provides immediate correction to misperceptions and misunderstandings; postBAT discussions allow for peer feedback

BATs are designed to engage all team members in problem-solving during course time, with an expectation of decision-making

Students within each team hold each other accountable; students interact with other groups publically, which encourages team efficacy

Team members have an opportunity to recognize and appreciate different ways of learning and understanding as the team brings its collective knowledge together for problem solving 
Chickering and Gamson's (1987) principles are grounded in the educational theories of Vygotskianism, Bandura's Social Learning Theory, and Zimmerman's Self-Regulated Learning (Bandura, 1977; Zimmerman, 1990). Vygotsky’s Social Development Theory argues that development cannot occur separate from social interaction, and that social development requires a more knowledgeable other and a zone of proximal development within which the more knowledgeable other can assist the ready learner to growth. Within the zone of proximal development, an individual who has a clearer understanding or a higher ability level is able to interact with the less able individual and, through shared experience, assist in learning of the task, process, or concept at hand (Vygotsky, 1987). In TBL, the teacher, and knowledgeable peers within the TBL group, serve in the role of the more knowledgeable other, and are able to facilitate understanding amongst all of the members of the group. Students are able to compare their understanding of material with the understanding of the other members of their group through the individual and readiness assurance test (iRAT/tRAT) process, which is inclusive of debate and consensus regarding key topics. During basic application tasks (BATs), students work together to come to decisions regarding the application of their understanding in real-world problems. The teacher and peers serve as guides and facilitators for development of the ability of all of the team members to apply their newly gained knowledge (Hrynchak \& Batty, 2012).

In TBL, students earn shared grades as well as individual grades, and members of the team who do not come to class prepared, suffer social pressure from their team. There is individual accountability, not just to the teacher, but also to other team members, that reduces "social loafing” (Michaelsen et al., 2008). Individual students are encouraged to engage at a higher level both by the desire to succeed, and the desire to avoid social disapproval. As each member of the team increases his or her engagement, the group as a whole sees improved 
outcomes, and self- and collective-efficacy is developed. This in turn results in changes in the way that students decide which tasks to engage in, how much time and energy to spend on tasks, and desired levels of achievement.

Bandura (1986) presented a theoretical framework - the Social Learning Theory - that explained the interconnectedness of behavioral, personal, and environmental factors that led to learning. According to the Social Learning Theory, social interaction is fundamental to learning, and learning must occur first within an interpsychological context (a social context), before it can be internalized in an intrapsychological context. Bandura (1986) specifically spoke to the individual's self-regulatory capabilities that effect thought processes, motivation, affective states, and behaviors and that ultimately lead to monitoring of behavior, comparison of that behavior to a model, and modification or retention of that behavior. Bandura proposed that individuals form intentions and then develop plans and strategies for realizing those intentions. They must set goals and anticipate outcomes that then motivate them toward changes in behavior (Bandura, 2005). According to Bandura's theory, people do not only plan for success, they also adopt personal standards that they believe will lead to success, and monitor and regulate their actions in order to give themselves satisfaction and a sense of self-worth and to refrain from actions that bring self- and social-censure. This personal agency functions within an extended web of human social interaction; consequently, it functions within environments, whether imposed, selected, or created. When required to perform within an imposed environment, such as a classroom structure, individuals with a high sense of self-efficacy see the potential opportunities presented by the environment; those with a low sense of self-efficacy tend to dwell on problems, obstacles, and risks. Self-efficacy also influences task choice, expenditure of effort, persistence on task, and achievement; individuals with high self-efficacy work harder, persist longer, and achieve at a 
higher level than those with low self-efficacy. Belief in personal and collective efficacy influences how individuals organize, create, and manage the potentiality of the environment (Bandura, 2005). TBL begins with the creation of teams, which serve as the social context within which students approach and acquire an understanding of new material. TBL promotes the development of high-functioning teams, which require high levels of involvement by all of the team's members, team identification, and the ability to use complex thought processes resulting in evidence that the whole is greater than the sum of its parts (Thompson et al., 2015). By holding individuals accountable to teams through the requirement for self-directed learning, students begin to develop self-regulating behaviors (Michaelsen et al., 2008). Zimmerman (1990) built upon earlier models, and developed a list of attributes of self-regulating learners. He stated that self-regulated learners know what they do and do not know, and seek out means for mastering content. Metacognitively, they plan, set goals, organize, self-monitor, and self-evaluate at various points during the process of knowledge acquisition. Zimmerman postulated that self-regulation depends on continuing feedback of learning effectiveness. Selfregulated learners are motivated to acquire knowledge through systematic and controlled processes, and they accept responsibility for their achievement outcomes (Borkowski, Carr, Rellinger, \& Pressley, 1990). Self-regulation training has been shown to improve not only students' learning, but also their perceptions of self-efficacy, and consequently, their motivation to self-regulate (Zimmerman, 1990).

Schunk and Zimmerman (1997) expanded Zimmerman's earlier model, and Bandura's model, postulating that successful adaptation to school requires the development of selfregulation. Self-regulation is oriented toward goal attainment and is inclusive of cognition, behavior, and affect. Successful self-regulation in the educational environment includes 
processes of time management, attendance to and concentration on instruction, organizing, rehearsing, and coding information strategically, establishing a productive work environment, and using social resources effectively (Schunk \& Zimmerman, 1997; Zimmerman, 1990). Modeling, by peers or teachers, is an effective means of promoting students' academic achievement and associated self-efficacy beliefs (Schunk \& Zimmerman, 1997). Team-based learning may function as a means by which self-regulation can be developed, since students must prepare for class through pre-class reading and self-study. Students are able to gauge their comprehension of pre-class material though the iRAT/tRAT process, and by comparison with that of their team members. Through the use of high-functioning teams, TBL provides less able students with models that encourage the growth of the individual's self-efficacy. Additionally, more able students improve their understanding as members of the group debate the nuances of material, critically work through possible options, and apply knowledge to make decisions.

Team-based learning is a form of active learning. Active learning has been found to be more successful in producing self-regulation in students than traditional, lecture-focused instruction (Michaelsen et al., 2014). Sungur and Tekkaya (2006) found that, when comparing two large groups of students who either received traditional lecture instruction or who engaged in problem-based learning (PBL), PBL students had higher levels of intrinsic goal orientation, task value, use of learning strategies, critical thinking, metacognitive self-regulation, effort regulation, and peer learning. PBL and other cooperative, collaborative, and active learning has also been found to increase academic achievement; improve students' attitudes towards each other; increase self-esteem, self-direction, and role taking abilities; improve students' sense of responsibility for their own learning and teach students the skills necessary for life-long learning (Griffith, 1990). These same benefits may not be developed in a lecture-based course. 
Active learning is more likely to fulfill the principles outlined by Chickering \& Gamson (1987) and it allows students the opportunity to actively construct learning through experience, both individually and socially. Bandura's Social Learning Theory, which outlines the interconnectedness of behavioral, personal, and environmental factors that lead to learning supports the use of active learning (Bandura, 1986). Lecture, which enables an expert to deliver information to groups of any size, is by its nature less likely to involve direct student-faculty contact (Jones, 2010, as cited in Mennenga, 2010). Lecture also does not encourage cooperation among students, nor does it encourage active learning. It is, in fact, notably passive (Mennenga, 2013). In contrast, active learning, when well constructed, not only meets Chickering and Gamson's (1987) principles, but also allows for prompt and specific feedback, emphasizes time on task, communicates high expectations, and respects diverse talents and ways of learning (Chickering \& Gamson, 1987). The application of these principles connects directly to Schunk and Zimmerman's (1997) model of successful adaptation to the learning environment through self-regulation. Collaborative and cooperative learning are two related but different strategies that have proven effective in teaching difficult material (Breneiser et al., 2012; Davidson et al., 2014; Johnson et al., 2014). Cheong (2010) defines cooperative learning as an instructional method inclusive of several key elements originally outlined by Oxford (1997). The key elements include positive interdependence, accountability, team formation, team size, cognitive development, and social development (Cheong, 2010). Cooperative learning, as compared to collaborative learning, is far more structured and prescriptive. Collaborative learning is based on the principles of Vygotskianism, including the zone of proximal development, and scaffolding. Both teaching strategies have the additional advantage over lecture of developing students' communication, teamwork skills, and critical thinking skills. Additively, Chung and Jackson 
Behan (2010) found group learning associated with collaborative learning activities motivated students (Chung \& Jackson Behan, 2010; Lunstroth, 2014; Vanderzalm et al., 2013).

\section{Assumptions}

This study assumed that the achievement of learning outcomes in a difficult course can be improved through the use of an instructional method that encourages students to participate in teams with other learners, provides immediate feedback, increases self-efficacy, and provides opportunities to apply newly gained learning. It also assumes that the characteristics of the two cohorts of students were equivalent due to the application requirements of the physical therapist assistant program and college. It is assumed that students had varying academic and team skill abilities, and that these were equitably divided across teams. An assumption is made that no curriculum or policy changes occurred between the two cohorts that fundamentally altered their consistency. Finally, it is assumed that there were no differences in teaching beyond the method of content delivery, between the two groups of students that would result in the observerexpectancy effect or other cognitive bias resulting in subconscious influence on the participants in the study, as the instructor was unaware at the time of course delivery that a study would result from the effort.

The following assumptions are also being made in the design of this study, and are required for ANCOVA:

- Each group of students studied is drawn from a normally distributed population.

- Both samples are drawn independently of each other.

- Within each sample, observations are independent of each other.

- Factor effects are additive. 
- The relationship between the instructional method used and the achievement of learning outcomes is linear.

- The lines expressing these linear relationships are parallel (homogeneity of regression slopes).

- The covariates are independent of the treatment effects (Hazard Munro, 2004).

\section{Limitations and Delimitations}

\section{Limitations}

This study used a nonrandomized sample of second-year PTA students enrolled in a neurorehabilitation course from two nonconsecutive years. The study sample is homogenous and therefore cannot be considered representative of all PTA students. Use of a nonrandomized sample limits the ability to infer causality of the findings. Additionally, the study used a small sample size, of two cohorts of seventeen and sixteen students respectively.

Students were able to take the NPTE-PTA in January or in April following graduation and, although these examinations are standardized to meet the content outline, they were made up of different questions due to the scheduled testing system of the Federation of State Boards of Physical Therapy (FSBPT), which creates four different but equal examinations given over the course of any one year, on set test dates. Also, there may be a different number of neuromuscular and nervous system questions, so long as the number of questions falls within the content outline's requirements. The FSBPT Test Content Outline requires that, for the Neuromuscular and Nervous System, each examination include: 8-10 questions for Data Collection; 10-11 questions for Diseases/Conditions that Impact Effective Treatment, and 13-14 questions related to Interventions (Federation of State Boards of Physical Therapy, 2013). Data 
collected for this study was analyzed using ANCOVA, which presents additional limitations. The use of ANCOVA to adjust for initial differences may result in misleading interpretations, and standard ANCOVA may be inappropriate if the correlations between the covariate and dependent variable are not equal across groups (J. R. Thomas, Silverman, \& Nelson, 2015).

\section{Delimitations}

Delimitations include the inability to generalize findings, due to the subjects in both groups being second-year PTA students from one physical therapist assistant program at a small, proprietary college in Middle Tennessee. The study consisted of small sample sizes, with one group made up of seventeen students, and one group made up of sixteen students. Additionally, all of the students in the study were selected for the program using a specific set of criteria and a point system that improved likelihood of selection based on GPA, previous college attendance, and interview performance. The study comprised one second-year neurorehabilitation course. Consequently, there is no intention to generalize findings to other PTA programs or to other courses in the PTA curriculum. The study did allow for comparison of results from two groups of students who experienced different teaching strategies.

The TBL course was created utilizing the well-established configuration created by Michaelsen (Michaelsen et al., 2008). No modifications were made to Michaelsen's structure and peer members of the Team-Based Learning Cooperative reviewed select individual units. However, this was the first course created by the teacher using TBL. Finally, there is a one-year gap between study groups. The lecture course was taught in the fall of 2013; the TBL course was taught in the fall of 2015. During the intervening year, the first iteration of the TBL course was fully developed and piloted. The learning outcomes for the students who were taught in the 
first iteration of the TBL course were utilized to evaluate the content validity of the in-course examinations.

\section{Definitions of Terms}

The following definitions and descriptions are presented to clarify terms used in this study.

\section{Traditional Lecture-Based Model}

The traditional lecture-based classroom model refers to an instructor led, face-to-face teaching model in a formal classroom setting. The instructor determines the content, presentation, learning activities and assessment methods. The lecture-based model was a tenweek lecture and lab practice course that was delivered over three, three-hour days each week. Students were required to complete reading in the course textbook and answer homework questions prior to attending class. The three-hour class periods included approximately 90 minutes of lecture time that utilized PowerPoint, handouts, and video presentations. Students then participated in a lab that included instructor demonstrations, skills practice with peers, and case studies.

\section{Team-Based Learning Model}

Team-based learning is a teaching strategy that is based around units of instruction that are taught in a three-step cycle: pre-class preparation, in-class readiness assurance activities, and application-focused activities. Team-based learning is characterized by the formation of small, heterogeneous student teams; individual student accountability to the team and to the instructor; frequent and immediate feedback; and the application of course content to real-world activities (Michaelsen et al., 2004). These criteria were used for the delivery of the course material in accordance with Michaelsen et al. (2008). The team-based learning course was composed of 
eight modules that included all content included in the lecture-based model. Course policies and examinations remained the same.

Assignment to student teams. Students were assigned to teams based on known characteristics including previous achievement level, demonstrated success working in teams, relative extroversion/introversion, previous exposure to the clinical setting, and previous experience as physical therapy technicians. Students were assigned with the intention of ensuring homogeneity in so far as possible, ensuring that teams would include a variety of student resources and skills, and that student characteristics would be evenly distributed across groups. Three teams were created, two with five members each, and one with six members.

Readiness assurance process. The readiness assurance process was designed to hold students accountable for pre-class preparation. Readiness Assurance Tests consisted of ten to twenty multiple choice questions that covered essential content presented in the pre-class assignment. Readiness Assurance Tests (RATs) were first taken individually by students (iRATs), and then by the team working together (tRATs). Team members discussed and reached consensus on the questions on the RAT and entered them onto Immediate Feedback Assessment Technique Forms (IF-AT).

Frequent and immediate feedback. The IF-AT Forms are keyed scratch-off forms that provided teams with immediate feedback regarding their response. Teams were able to make a second and third attempt at selecting the correct answer to a question, with declining point value for each attempt. Each student was provided feedback through the discussion and answer process for completion of the tRAT, as he or she was able to compare his/her own responses and understanding of concepts. The team received immediate feedback when selecting an answer, as correct responses are identified on the IF-AT. Following completion of the tRAT, an 
abbreviated lecture was provided to allow students to ask questions and to permit the instructor to address content that remained unclear.

Basic Application Tasks. Activities for the team-based learning course were designed to promote students' application of understanding of the content and clinical reasoning. Basic Application Tasks (BATs) included case scenarios, multiple choice questions, and opportunities for the design of patient treatment plans for simulated patients. Each team discussed, researched, and decided on responses to questions and cases that required that specific decisions be made. All teams then presented these decisions simultaneously, followed by discussion amongst teams.

\section{Chapter Summary and Organization of the Remainder of the Study}

Chapter one presented the theoretical framework under which this study was undertaken. It introduced the background of the study, the problem statement, and the research questions and hypotheses that guided the study. Team-based learning as an instructional method has the potential to increase retention in difficult courses within a physical therapist assistant program. Studies of TBL have demonstrated that TBL encourages students to participate with other learners, provides immediate feedback, increases self-efficacy, and provides opportunities to apply newly gained learning, all of which are elements of collaborative and cooperative learning (Michaelsen et al., 2008). These two related but different strategies have proven effective in teaching difficult material (Breneiser et al., 2012; Davidson et al., 2014; Johnson et al., 2014).

Chapter 2 will present a review of the literature that supports the design of the study. It will encompass literature related to retention in healthcare, neurophobia, different forms of active learning, and the use of TBL in various healthcare education programs. Chapter 2 also outlines the manner in which TBL courses are designed and delivered. Chapter 3 will present a discussion of the methodology and research design of this study. Chapter 4 will present the 
findings and statistical analysis; Chapter 5 will include further discussion regarding the results of the study and recommendations for further research.

\section{CHAPTER 2: LITERATURE REVIEW}

\section{Introduction}

The purpose of this study was to compare the effectiveness of traditional, instructor-led, lecture-based learning with team-based learning, on learning outcomes, for undergraduate physical therapist assistant students enrolled in a neurorehabilitation course at a small, proprietary college in Middle Tennessee. This chapter describes the current instructional climate in allied health education, introduces the conceptual model that guided the study, and provides an overview of how that model can be applied to team-based learning. A review of the literature related to TBL in multiple educational fields is presented. In addition, the components of teambased learning are reviewed.

\section{Review of Pertinent Literature}

\section{Retention In Healthcare Education}

Student attrition is a concern for medical and allied health programs of all types (Ascend Learning LLC, 2012). Medical, nursing, pharmacy, and other programs may report elements of attrition differently, but in general, attrition can be understood as the departure from or delay in completion of a program of study or some component of its requirements. There are consequences of this attrition including financial costs for students and government agencies; loss of time and resources for faculty, institutions, and support teams; and, for selective programs, the loss of a class placement for a different student - one who might have succeeded (Schneider \& Yin, 2011). Commitment (Clements, Kinman, Leggetter, Teoh, \& Guppy, 2016), level of self-efficacy, faculty support, outcomes expectations (Griswold, 2014), and 
dissatisfaction with clinical placement (Hamshire, Willgoss, \& Wibberley, 2012) have all been reported as reasons for early attrition in medical and nursing programs. Establishing preadmission requirements, such as prerequisite course Grade Point Average (GPA), standardized test scores, non-cognitive factors such as reference letters and interviews, and requirements for community service or observation hours have all been utilized to improve retention (Sanderson, 2014), however identification of factors that result in attrition after a student has entered a program of study remains difficult to identify and mitigate (Wells, 2007).

\section{Retention in Physical Therapy Education}

Physical therapy education is inclusive of physical therapist and physical therapist assistant programs. Maring, et al. reported that while there is literature that predicts student academic success for nursing students, there is little literature that addresses physical therapy students and even less literature concerned with physical therapist assistant students (2016). Physical therapist assistant (PTA) programs require an average of 68.1 weeks to complete and cost between $\$ 20,020$ and $\$ 55,631$ in tuition, fees, and other expenses. Graduation rates range from $41.7 \%-100 \%$ in accredited programs, with an average first time pass rate for the licensure examination of $85.9 \%$ (American Physical Therapy Association, 2015a). Most PTA programs employ selective admissions, which attempt to utilize cognitive and non-cognitive factors in admission decisions. Regardless, an average retention and graduation rate of $81 \%$ indicates that admissions criteria may not be sufficient to ensure retention (Maring et al., 2016).

The majority of students who withdraw from programs or who fail to meet the standards in physical therapist assistant education do so for academic reasons (Maring et al., 2016). Coursework designs are based on the accrediting standards of the Commission on Accreditation in Physical Therapy Education, which dictate the requirements to teach fifty-three specific 
intervention-related competencies, in addition to elements of communication, professionalism, ethics, and management. All of these mandated elements must be taught within a time period of less than twenty-four months, and are inclusive of general education requirements for an associate degree (Commission on Accreditation in Physical Therapy Education, 2016). Courses are academically robust, and achievement of high grades is challenging due to rigorous grading systems. Additionally, programs tend to establish high minimal grades for passing both written and practical examinations, and limited opportunities for retaking failed exams. For example, for the program in which this study was based, students must earn a minimum of a $75 \%$ on all written and practical examinations. Practical examinations are graded utilizing rubrics that require evaluation of all elements of intervention skills, and, should a student fail to perform successfully, only one retake is allowed. A student who fails the retake examination is dismissed from the program due to a failure to meet academic standards.

\section{Neurology and Neurophobia in Healthcare Education}

One of the most difficult courses students in any medical or allied health program take is neurology (Anderson, 2012; Flanagan et al., 2007; McColgan et al., 2013). Neurology and neurorehabilitation are essential courses, primarily as clinicians will be responsible for caring for individuals with neurological disorders, and secondarily due to the percentage of the licensure board related to the neurological system (Federation of State Boards of Physical Therapy, 2013). The current NPTE-PTA Test Content Outline mandates that between 31-35 questions of the 150 questions on the licensure exam be related to the neuromuscular and nervous systems, in the domain of data collection, diseases and conditions, or interventions. As a comparison, the acceptable range for cardiovascular/pulmonary and lymphatic systems is $23-26$ questions; musculoskeletal system is 37-41 questions, and other system is 19-30 questions (Federation of 
State Boards of Physical Therapy, 2013). Question percentages in the content outline are reflective of the percentages of patients with these disorders that are commonly seen by practicing physical therapist assistants (Federation of State Boards of Physical Therapy, 2013).

Yang et al. report that students perceive neurology as being overly complex, abstract, and far more difficult than other disciplines (Yang et al., 2014). According to McColgan, the real fear of neurology students experience may hinder neurology education. Fear of studying neurology has been given the name "neurophobia" (Anwar et al., 2015) and has been recognized in medical students, allied health students, and nursing students (Anderson, 2012; Flanagan et al., 2007; McColgan et al., 2013). Instructional strategies utilized to teach neurological topics include lectures, skill demonstrations and practice, problem-based learning (PBL), online learning, video presentations, clinical conferences, and more recently, team-based learning (Anderson, 2012). Among these teaching strategies, the most successful teaching approach includes some elements of active learning and clinical problem solving (Anwar et al., 2015).

\section{Theoretical Framework That Supports the Selection of Team-Based Learning as an}

\section{Instructional Strategy}

Chickering and Gamson (1987) outlined seven principles for good practice in undergraduate education in their seminal article. These principles are grounded in Vygotskianism (Vygotsky, 1987), Bandura's Social Learning Theory, and Zimmerman's Self-

Regulated Learning theory (Bandura, 1977; Zimmerman, 1990). Chickering and Gamson (1987) stated that good practice:

- Encourages contact between students and faculty

- Develops reciprocity and cooperation among students

- Encourages active learning 
- Gives prompt feedback

- Emphasizes time on task

- Communicates high expectations

- Respects diverse talents and ways of learning

Vygotsky's Social Development Theory stresses the importance of the social interaction within which learning occurs. He proposed that community plays a vital role in the learner's development of making meaning of what is being taught. Additionally, he stated that learning required the presence of a more knowledgeable other, who could meet the learner within the “zone of proximal development" (Vygotsky, 1987). - an area in which individuals could come together to learn (Vygotsky, 1987). According to the Social Development Theory, social interaction is fundamental to learning, and that learning must occur first within an interpsychological context (a social context), before it can be internalized in an intrapsychological context. The shared experience of the less and more able learner results in an interaction wherein an individual with greater experience and understanding can assist an individual with less understanding (Vygotsky, 1987).

Bandura (1986) theorized in his Social Learning Theory the interconnectedness multiple factors that lead to learning. The Social Cognitive Theory takes into account the thought processes, motivation, affective states, and behaviors that ultimately lead to monitoring of behavior, comparison of that behavior to a model, and modification or retention of that behavior. Bandura proposed that individual personal agency functions within the connectedness of social environments and interactions that encourage the creation of plans and strategies for meeting one's own goals and intentions. The setting of goals creates motivation to succeed and results in the monitoring of behavior and modification of behavior. In the context of Bandura's theory, 
one would compare his or her behavior to that of a successful model, and modify his own behavior accordingly (Bandura, 1986). Changes in behavior result in personal achievement of goals, and achievement leads to improved self-efficacy (Bandura, 2005).

Zimmerman (1990) developed a picture of the self-regulated learner, one whose behavioral modifications have resulted in improved self-efficacy and academic success. The self-regulated learner plans, sets goals, organizes, self-monitors, and self-evaluates at various points during the process of knowledge acquisition. Zimmerman postulated that self-regulation depends on continuing feedback of learning effectiveness (Schunk \& Zimmerman, 1997; Zimmerman, 1990). Self-regulated learners are motivated to acquire knowledge through systematic and controlled processes, and they accept responsibility for their achievement outcomes (Borkowski et al., 1990).

The self-regulation discussed by Zimmerman is a necessary component of academic success (Schunk \& Zimmerman, 1997). Learner strategies that lead to success include time management, attendance to and concentration on instruction, organizing, rehearsing, and strategically coding information, establishing a productive work environment, and using social resources effectively for self-regulation (Schunk \& Zimmerman, 1997; Zimmerman, 1990). Research supports the effectiveness of modeling, by peers or instructors, as a means of promoting students' academic achievement and associated self-efficacy beliefs (Schunk \& Zimmerman, 1997).

Active learning has been found to be more successful in producing self-regulation in students than traditional, lecture-focused instruction (Ruckert et al, 2014). Sungur and Tekkaya (2006) found that, when comparing two large groups of students who either received traditional lecture instruction or who engaged in problem-based learning (PBL), PBL students had higher 
levels of intrinsic goal orientation, task value, use of learning strategies, critical thinking, metacognitive self-regulation, effort regulation, and peer learning. These findings were supported by a Sangestani and Khatiban (2013) who found that even the addition of PBL to traditional lecture improved application of theory in clinical practice, increased learning motivation, and enhanced activity in class. PBL as compared to lecture has been found to increase academic achievement; improve students' attitudes towards each other; increase selfesteem, self-direction, and role taking abilities; improve students' sense of responsibility for their own learning and teach students the skills necessary for life-long learning (Griffith, 1990).

Active learning results in fulfillment of the principles outlined by Chickering \& Gamson (1987). Active learning provides students with individual and social occasions to actively construct learning through experience. Lecture, which enables an expert to deliver information to groups of any size, is by its nature less likely to involve direct student-faculty contact (Jones, 2010, as cited in Mennenga, 2010).

Chickering and Gamson (1987) offer the following suggestions for meeting the needs of undergraduate students in support of the above-cited theories:

- Encourage contact between students and faculty by establishing resource groups that include peers and faculty.

- Develop reciprocity and cooperation among students by making learning a team effort. Establish learning groups within which students work together to solve problems set by the instructor.

- Encourage active learning by use of structured exercises, discussions, projects and other means of getting students to talk and write about what they are learning, relate it to past experiences, and apply it to their daily lives. 
- Give prompt feedback by ensuring that students know what they do and do not know, through appropriate and frequent feedback regarding performance and including suggestions for improvement.

- Emphasize time on task by allocating realistic amounts of time for activities, and by providing opportunities for students to integrate studies into the rest of their lives.

- Communicate high expectations for everyone - "for the poorly prepared, for those unwilling to exert themselves, and for the bright and well-motivated" (Chickering \& Gamson, 1987, p. 5).

- Set high standards for individuals and groups, and expect students to hold high standards for each other.

- Respect diverse talents and ways of learning by creating an environment in which students can show their talents and share them with others, while challenging the students to learn in ways that may not come easily for them.

\section{Active Learning Strategies vs. Passive Learning Strategies for Improved Outcomes in Healthcare Education}

Instruction via lecture remains the most common teaching method used in medical education. Lecture is teacher-centered and discipline based, and is an efficient method that allows for the delivery of current, up-to-date information to a class of any size (Altintas et al., 2014). However, due to its passive nature, lecture may not prepare students to critically think about material, or to make clinical decisions. Research demonstrates that the development of critical thinking is inversely proportional to the amount of time that students spend passively listening, and retention of passively delivered material is poor, even when students are provided with a rich summary of the material covered in lecture (Altintas et al., 2014). Consequently, 
medical and allied health educators are challenged to identify teaching strategies that increase student engagement and result in meaningful learning. Active learning, as compared to lecture, has been proven to increase student learning through interaction and discussion among student peers (Janssen, Kirschner, Erkens, Kirschner, \& Paas, 2010).

Active learning can be defined as any instructional method that requires that students partake in meaningful learning activities that require not just participation, but also thinking about participation. In practice, active learning takes place in a classroom environment, and is not inclusive of homework or other types of projects that students do independently outside of the classroom. Active learning has been found to improve student attitudes, thinking, and writing (Prince, 2004). Johnson et al. (2014) found statistically significant effects for active learning correlated with improved academic achievement, quality of interpersonal interaction, student self-esteem, and perception of social support. Springer, Stanne, and Donovan (1999) supported these findings, and also cited improved retention in academic programs.

One method of active learning - collaborative learning - refers to an instructional method requiring students to work together in small groups, toward a common learning goal (Prince, 2004). Collaborative learning encompasses cooperative learning, including the division of responsibilities among team members. Cooperative learning is a form of group work wherein students pursue learning goals together but are assessed individually. One collaborative and cooperative instructional strategy that has a long history of use in medical and allied health education is problem-based learning (PBL), in which a relevant problem is introduced at the inception of a learning cycle. The problem is addressed at different levels throughout the cycle, and serves as the context within which students pursue an understanding of a particular clinical 
concept. PBL typically involves a good deal of self-directed learning, both individually and within the small group (Prince, 2004).

According to Lou et al. (1996) cooperative learning is a strategy that can be employed to encourage active learning. Cooperative learning, as described in Elberson, Vance, Stephenson, and Corbett (2001), is a structured, systematic instructional strategy used in small groups to achieve a common goal. Eng (2009) outlines the following eight principles of cooperative learning that encourages active learning: 1) students who engage in cooperative learning learn more and are more successful academically; students learn to listen to others' views, to share ideas, and to construct new understanding; 2) students should be organized into heterogeneous groups, which encourage individuals of different backgrounds, genders, ages, and experiences to work together and to generate more ideas from multiple perspectives; 3 ) members of groups that have common goals often help one another to learn; 4) cooperative learning encourages individual accountability, which results in group success; 5) equal opportunity for participation must be encouraged through specific techniques that eliminate the potential for one or two group members to dominate, or for a group member to avoid contributing to the group; 6) peer interactions in cooperative groups offer opportunities for students to engage in active knowledge construction; 7) cooperative learning encourages students to not only learn course material, but also to develop team work and collaborative skills, such as taking turns and checking others' understanding; 8) students who are granted autonomy take responsibility for their own learning, and may practice metacognitive skills that inform as to how and what might be done to improve understanding (Eng, 2009). Eng's principles result in the common characteristics of cooperative and collaborative learning structures: 1) students organized into small groups focused on a common learning objective; 2) interdependence within the group; 3) group members attempt to 
help one another; and 4) there is individual and group accountability (Breneiser et al., 2012). In 2003, the Institute of Medicine published a list of five key competencies for healthcare clinicians including: 1) delivering patient-centered care, 2) practicing in interdisciplinary teams, 3) using best evidence, 4) applying quality improvement, and 5) using informatics (Ruckert, McDonald, Birkmeier, Walker, Cotton, Lyons, Straker, \& Plack, 2014). Cooperative and collaborative learning prepare future clinicians to work in the clinical environment by encouraging the attainment of competencies as outlined by the Institute of Medicine (2003).

While the terms "cooperative learning" and "collaborative learning" are often used interchangeably, cooperative learning is more likely to involve a division of responsibilities among group members, while collaborative learning refers to members of a group engaging in a continuous mutual effort to reach a learning goal. Regardless of terminology, cooperative and collaborative learning methods share the elements cited above (Janssen et al., 2010) and, as reported in Prince (2004) promote a broad range of learning outcomes, particularly improved academic achievement, students' attitudes, and student retention.

\section{Team-Based Learning In Healthcare Education}

Team-based learning (TBL) is a method of collaborative learning that is gaining acceptance as an instructional technique appropriate for medical and allied health education. First used in a health professions course at the Baylor College of Medicine in 2001 (Haidet et al., 2014), TBL has found a place at multiple schools of medicine, nursing, pharmacology, dentistry, and to a limited extent, physical therapy. However, studies of the effectiveness of TBL as a means of improving learning outcomes present inconsistent results, often due to the lack of uniformity between approaches, measurement of results, methods of reporting, or the utilization of only parts of the overall TBL method as described by Michaelsen, the method's founder 
(Fatmi et al., 2013). Fatmi et al. (2013) reported that, when currently available research was assessed for consistency with the specifics of team-based learning as described by Michaelsen, only fourteen of over three hundred studies were identified as consistent.

\section{Team-Based Learning In Medical Education}

Burgess et al. (2014) found that, of 147 publications related to the use of TBL in medical education, only 20 articles satisfied the inclusion criteria, which required that articles reported original research, and the research design included the seven core TBL design elements (team formation, readiness assurance, immediate feedback, sequencing of in-class problem solving, and Michaelsen's four Ss [significant problem, same problem, specific choice, and simultaneous reporting], incentive structure, and peer review). TBL programs reviewed were implemented in a wide-range of undergraduate medical curricula, primarily during preclinical training. They were implemented in class sizes ranging from 20 to 240 students, with teams ranging from 4 to 12 students each. Methods of structuring the TBL course content were summarized according to Haidet et al.'s reporting guidelines (Haidet, Levine, Parmelee, Crow, Kennedy, Kelly, Perkowski, Michaelsen, \& Richards, 2012). Even among these 20 studies, some variability remained. For instance, courses were divided into 2 to 8 units, the number of multiple-choice questions on iRATs and tRATs ranged from 3 to 10, one study did not include the incentive structure, and almost half of the articles did not report on the peer review element of TBL (Burgess et al., 2014).

Thompson, Schneider, Haidet, Levine, McMahon, Perkowski, and Richards (2007) reported on the utilization of TBL at ten medical schools. The courses within which TBL was used included some or all elements of TBL. For some applications, only one unit was taught using TBL, while other units were taught via traditional lecture. This qualitative study reported 
that the addition of TBL to medical curricula resulted in positive faculty response and student engagement, to include improved student attendance (Thompson et al., 2007).

The use of TBL in medical education has demonstrated improvement in student test scores, both during the course and in final examinations (Anwar et al., 2015; Hamshire et al., 2012; Hashmi, 2014; Mody, Kiley, Gawron, Garcia, \& Hammond, 2013; Weiner, Plass, \& Marz, 2009), a favorable response from students and improved student engagement (Anwar et al., 2015; McMullen, Carledge, Levine, \& Iversen, 2013; Mody et al., 2013; Punja, Kalludi, Pai, Rao, \& Dhar, 2014; Weiner et al., 2009), improvement of team scores vs. individual scores (Brandler, Laser, Williamson, Louie, \& Esposito, 2014), higher scores on iRAT and tRAT multiple-choice questions and specific, board-related, module-based questions (Punja et al., 2014; Saudek \& Treat, 2015; Thomas \& Bowen, 2011). Tan et al. (2011) found higher scores in post-test for students who were in a TBL group vs. those in a passive learning group. Thus far, the Tan study is the only one to measure long-term retention of content, albeit only 48 hours post-course. Tan also found weaker students benefitted to a greater degree from TBL, than stronger students (Tan et al., 2011).

\section{Team-Based Learning in Nursing and Pharmacy Education}

Team-based learning also has a long history of use in pharmacy and nursing education. Allen et al. (2013) reported on the use of TBL in pharmacy education. The authors interviewed faculty members from seven US-based schools of pharmacy and reported that TBL was being utilized in pharmacy education in both elective and required courses, as a module or for an entire course, and utilizing either modified or standard TBL structure. Faculty respondents stated that TBL was an effective incentive for students to prepare for class and to be engaged, and that TBL was perceived to be more effective for fostering learning for each domain in Bloom's 
Taxonomy. Mixed reviews were given on TBL's effect on knowledge retention (Allen et al., 2013). As in the case of medical education, researchers found that TBL increased student engagement and teamwork values, and increased academic performance (Cheng et al., 2014; Clark et al., 2008; Currey et al., 2015; Maslakpak et al., 2015; H. A. Mennenga, 2013). Cheng et al. (2014) reported that academic effects were greater for weaker students. In one study (Harmon \& Hills, 2015), students reported increased study time and increased scores on a practice board examination. Ofstad and Brunner (2013) reported the additional outcome of improved communication skills and enhanced critical-thinking abilities in pharmacy students.

\section{Team-Based Learning in Physical Therapy Education}

Only one study was found that assessed the use of TBL in physical therapy education. Team-based learning was implemented in a gross anatomy course during the first semester of a three-year curriculum. Researchers found that students reported a significantly higher level of satisfaction with the course than did a previous cohort who did not participate in a TBL course (Livingston et al., 2014).

\section{The Structure of Team-Based Learning}

Team-based learning (TBL) meets the definition of collaborative learning, when used according to its original design, by engaging students in learning as members of heterogeneous small groups within which students develop interdependence and accountability to each other. In TBL, success is measured both for individuals in the group, and for the group as a whole, and so there is incentive for group members to come to class prepared, to help other members of their group, and to engage actively with course material to solve problems. Every aspect of TBL is designed to foster the development of self-managed teams, and students actively engage with each other as they solve authentic, instructor-designed problems through the application of 
course concepts (Michaelsen et al., 2014). Additionally, due to a design requiring pre-course exposure to pertinent material, a collaborative demonstration of knowledge and understanding, and then the majority of class time spent in team assignments focusing on the use of course content to solve the kinds of problems students are likely to see in future practice, TBL is designed to provide students with both conceptual and procedural knowledge (Michaelsen \& Sweet, 2008).

Team-based learning has four essential, foundational practices: 1) strategically formed permanent teams; 2) student familiarity with course material through a readiness assurance process; 3) the development of students' critical thinking skills through the use of carefully developed, in class application activities and assignments; and, 4) inclusion of a peer assessment and feedback system (Michaelsen et al., 2014; Michaelsen \& Sweet, 2008, 2011).

TBL requires the intentional formation of groups that have adequate resources and background to draw on, an equal distribution of resources across groups, and an avoidance of membership coalitions that are likely to interfere with the development of group coherence. By creating groups with members who bring a mix of experience, backgrounds, and perspectives together, a diverse approach to problem solving is assured. And while diversity may initially slow the development of cohesiveness, since teams are permanent, over time it becomes an asset. By avoiding coalitions within groups (by safeguarding against team members who might form a subgroup), newly formed groups are more likely to become unified and functional. Once designed, groups stay together for the length of the course or longer, which allows them to proceed through the normal life-cycle development of a purposeful, successful group (Michaelsen \& Sweet, 2008). 
Individuals within each group are accountable to the instructor and to each other for the quality and quantity of their course preparation and familiarity of course materials. Through the process of advance preparation, usually via the completion of assigned reading, team members strengthen themselves and their groups, and a lack of preparation limits the success of both the individual and the group as a whole. Lack of preparation by individual members also limits team development, as individuals who come to the group work prepared become frustrated and resentful with and resentful of team members who are not prepared. The readiness assurance process gauges both individual and group preparedness (Michaelsen \& Sweet, 2008, 2011). Following the readiness assurance process, groups engage in problem solving of realworld problems, which assess their ability to apply concepts learned in pre-class preparation. Effective group assignments follow the guidelines of Michaelsen's four S's:

- $\quad$ Significance - the problem, case, or question(s) should demonstrate concept usefulness. Problems should be relevant, real world, and important to the understanding of the course.

- Same problem - all groups within the class work on the same problem or case. Working on the same problem promotes within and between group discussions by creating a common frame of reference.

- Specific choice - groups should be required to use course concepts to make a specific choice. Students should be challenged to process information at the level of complexity that is required by application of concepts and decision-making based on those concepts.

- Simultaneous report - if possible, groups should report their choices simultaneously. Simultaneous report limits the effect that sequential reporting tends to have on groups 
that follow others, a result of which is the emergence of a majority view (Michaelsen \& Sweet, 2008, 2011).

Finally, TBL is inclusive of multiple peer assessment and feedback systems. First, individuals and groups receive immediate or near-immediate feedback from the readiness assurance process. Students first engage in an individual assessment, and then join with group members to repeat the assessment utilizing the combined preparedness of the group. Michaelsen, et al. recommend the use of IF-AT scratch off answer sheets, which result in the team receiving immediate feedback to their answer choices (Michaelsen \& Sweet, 2008). This real-time feedback enables team members to work together to correct misperceptions regarding the material learned, and it promotes the ability and motivation for teams to learn how to work together effectively by minimizing team domination of one or two members, or the avoidance of engagement by others (Michaelsen \& Sweet, 2008).

Students next have the opportunity to appeal the "right answer" through a written process that requires the defense of the students' answer choice. This encourages students to not only return to their pre-class reading assignments for clarification and support, but also to engage in peer-to-peer discussion as they develop their position. As a last step in the process, the instructor provides a focused review via lecture; lecture topics are based on any apparent misunderstanding of content revealed in the readiness assurance process.

Michaelsen, et al. (2008) reports the readiness assurance process as the backbone of TBL due to the promotion of team development in the following ways: 1) because students receive immediate feedback for both individual and team performance, each member becomes explicitly accountable for his or her preparedness; 2) team members work together in class and face-toface, which ensures immediate and personal impact from interactions; 3) students are motivated 
due to these interactions and in the interest of group success; and 4) cohesiveness of the group continues to grow even through the process of instructor review, as groups have the opportunity to celebrate together or learn together (Michaelsen \& Sweet, 2008).

Team-based learning follows a specific sequence, as outlined by Michaelsen (Michaelsen et al., 2004; Michaelsen \& Sweet, 2008). Described by Michaelsen as a "particular instructional strategy, not a series of independent small group activities" (2004, page 8), TBL is cyclical, and allows for an increasing level of exposure to and understanding of concepts by students (2004, page 8). This cyclical pattern is presented in Figure 1 below.

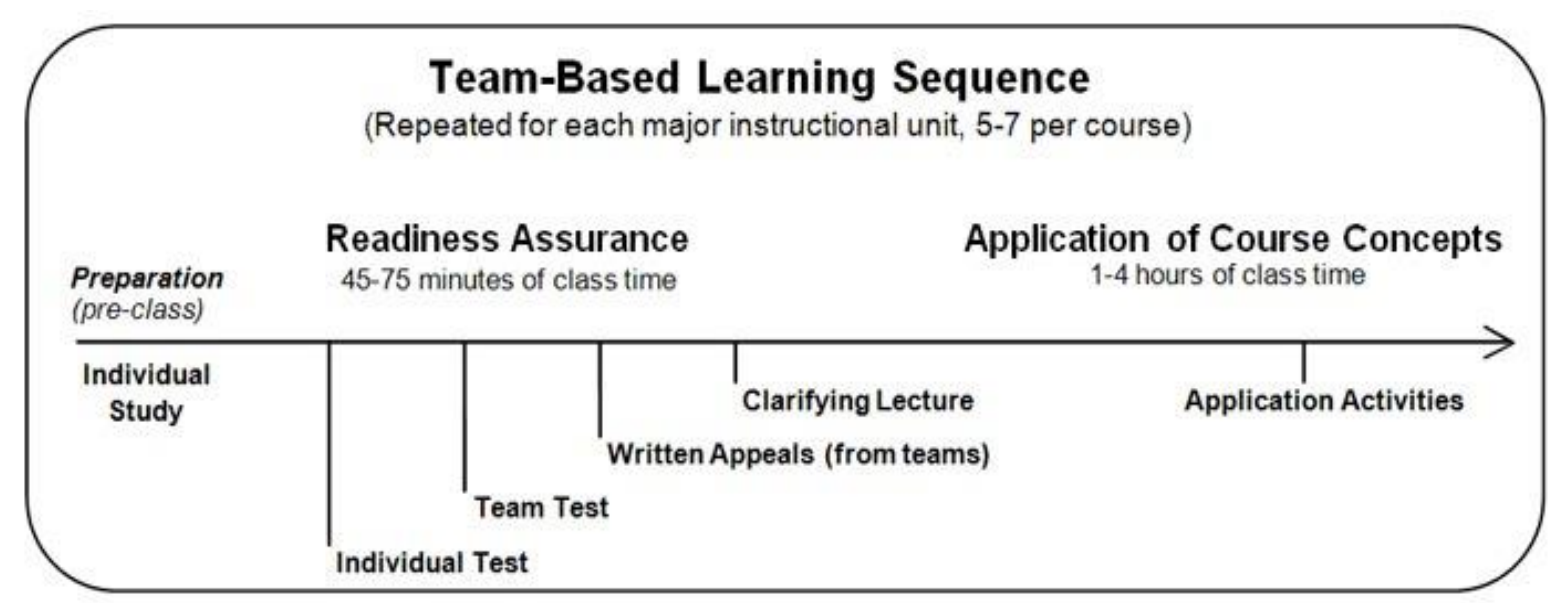

Figure 1 Team-Based Learning Instructional Activity Sequence. Reprinted from Team-Based Learning for Health Professional Education (p. 21), by L. K. Michaelsen, D. X. Parmelee, K. K. McMahon, and R. E. Levine (Eds.), 2008, Sterling, VA: Stylus Publishing LLC. Copyright 2008 by Stylus Publishing LLC. Reprinted with permission.

To paraphrase the process outlined by Michaelsen (2004), in step one, the preparation, or pre-class, phase is completed by students outside of the classroom prior to any in-class learning. Students are introduced to the unit material by following a reading guide provided by the instructor. The guide includes explanations and clarification of reading, links to additional 
material and supportive media, discussion questions, and other elements, all designed to give students a broad initial exposure to unit material.

Steps two through five include the four elements of the readiness assurance phase. In step two, students take an individual readiness assessment test (iRAT). The iRAT is short, encompassing ten to twenty-five questions, and focused on the main topics or big picture themes covered in the reading guide. Students record their answers on an answer sheet and in the margin of their test. Students are individually accountable for the iRAT; it measures their preparedness and level of understanding of the material covered in the pre-class work. In step three, the students take a team readiness assessment test (tRAT). The tRAT is exactly the same as the iRAT, and students come together in their groups with their copies of the test to discuss, learn from each other, and come to agreement on the best answer to the test questions. In order to provide immediate feedback, many TBL instructors use Immediate Feedback Assessment Technique (IF-AT) answer sheets. The IF-AT answer sheets provide real-time content feedback, as students scratch off their agreed-upon best answer (see Figure 2).

When student groups are unsuccessful on their first attempt, they can make a second, and if necessary, third attempt at selecting the correct response. Points earned decrease with each subsequent answer selection, which provides additional motivation for discussion and sharing of understanding between group members. The immediate feedback of the IF-AT method results in increased group discussion. 

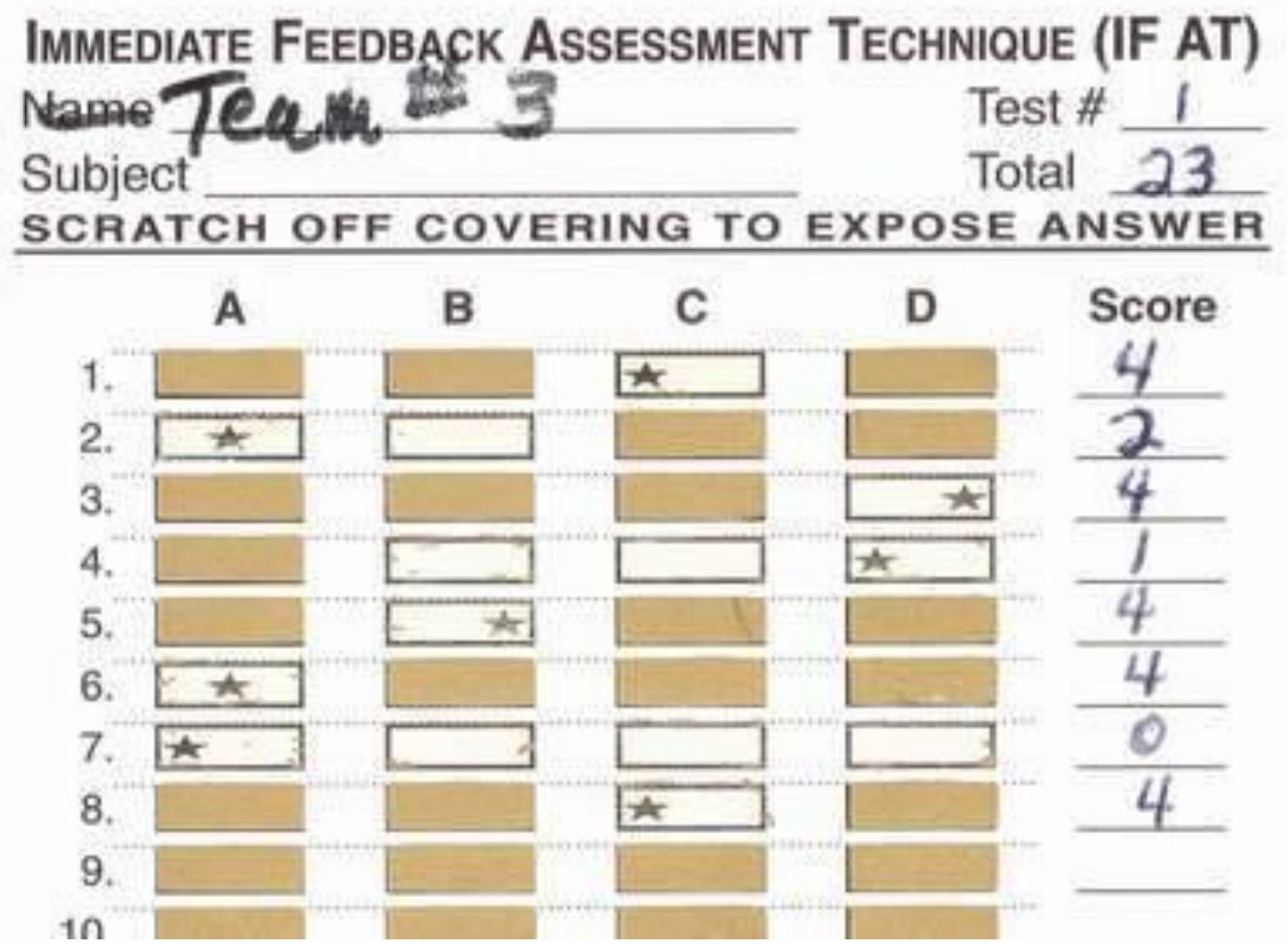

Figure 2 Immediate Feedback Assessment Technique. Reprinted from Team-Based Learning for Health Professional Education (p. 23), by L. K. Michaelsen, D. X. Parmelee, K. K. McMahon, and R. E. Levine (Eds.), 2008, Sterling, VA: Stylus Publishing LLC. Copyright 2008 by Stylus Publishing LLC. Reprinted with permission.

While students participate in the tRAT, the teacher grades the iRATs, in order to ascertain where students would benefit from feedback or additional information, the provision of which is the last step in the readiness assurance process. When students have completed the tRAT, they are given time to decide if and how they would like to appeal any of the answers on the test. A standard form is required that necessitates the development of a written argument and references to the resources from the pre-class materials to support the answer for which the students are arguing. The instructor collects the written appeals that the groups generate, and 
decides on the merit of the challenge after class, awarding points to the team that forwarded the successful argument.

Finally, in step five of the readiness assurance process, the instructor provides feedback to all of the students regarding content that students have had difficulty with, as demonstrated on iRAT and tRAT outcomes. Instruction on this content is presented in the form of a mini-lecture, usually not lasting longer than fifteen to thirty minutes. By the completion of the fifth step, students have been exposed to the course material four times - first, in the initial reading and study, second during the iRAT, third during the tRAT, fourth during their investigation into the material for support of appeals, and fifth during the instructor feedback. The entire readiness assurance process takes between 45 and 75 minutes of class time.

Following the readiness assurance process is the application of course concepts phase, made up of application-oriented exercises that require group members to work together to solve real-world problems or cases using the material covered in the unit. These cases or activities follow the four S's cited above, and differ significantly from many of the group activities students may have participated in previously. For TBL, activities require the input of the entire group - assigned tasks are too difficult for any one student to complete alone, however, through team collaboration, the group as a whole can succeed. Division of labor, which is a reasonable strategy for cooperative group work, does not work well with TBL activities, since the knowledge of all of the group members must be pooled for success. Also, TBL activities are completed during in class time, again encouraging engagement of every member of the group, but also eliminating students' concerns about social loafers who do not contribute or aggressive members who may take over the project. Groups must make decisions, and settle on a specific choice. Activities are specifically designed to require choices as opposed to products. And all of 
the groups make simultaneous report of their choices, accomplished through different methods that include holding up answer cards, posting answers for gallery walks, or other methods that limit any one group's influence over any others. Simultaneous reports encourage students to prepare to defend their answers, and provide a foundation for inter-group discussion.

The application phase can include one or more activities, progressing from simple to complex, and requiring progressively higher levels of critical thinking and decision-making. Each application phase per unit takes between 1 and 4 hours of class time, and as indicated below, can go through multiple cycles (see Figure 3).

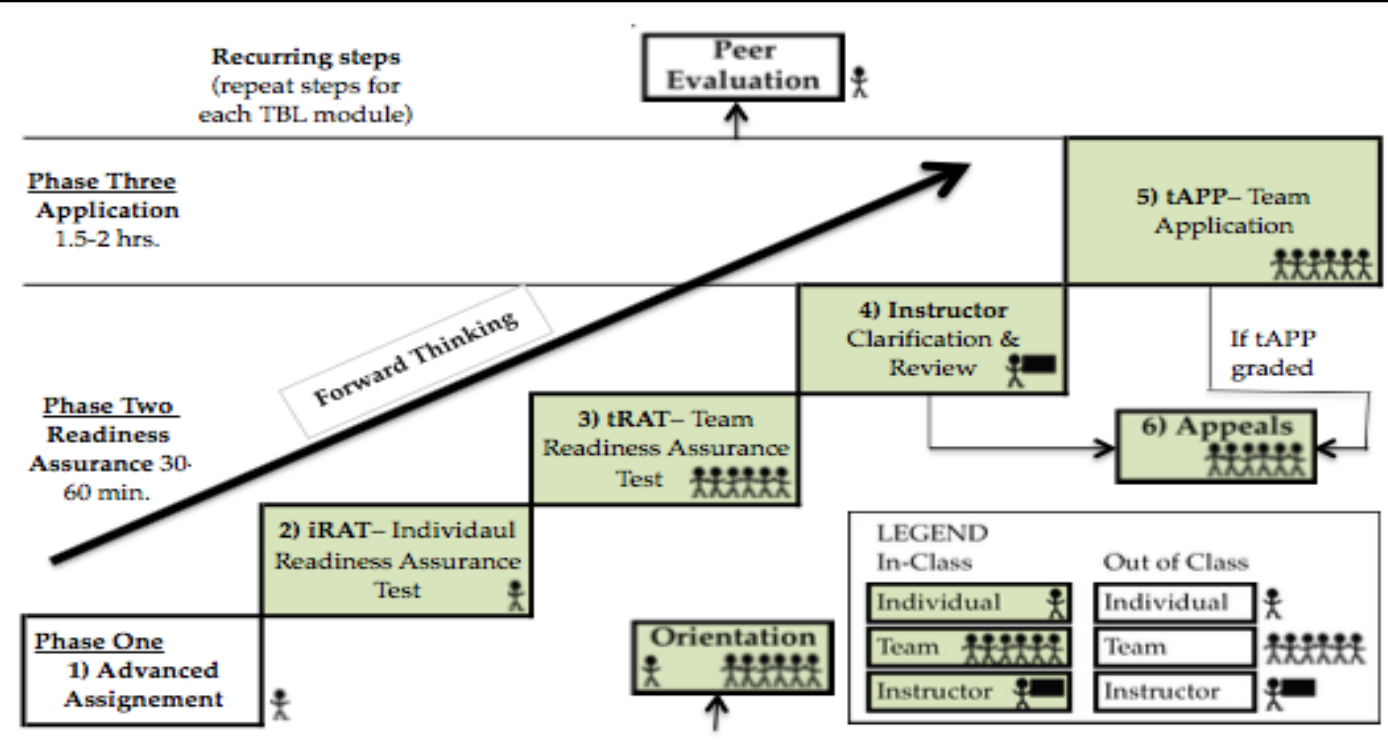

Figure 3 TBL Implementation Steps. Adapted from "Team Based Learning Practices and Principles in Comparison with Cooperative Learning and Problem Based Learning," by Michaelsen, et al, 2014, Special Issue on Learning Groups, Journal on Excellence in College Teaching, p. 62. Copyright 2014 by the Center for Teaching Excellence. Reprinted with permission. 
Finally, following one or more units, students take an individual comprehensive assessment test (iCAT), in order to assess their learning of the entire unit. The iCAT can be compared to typical examinations given during a lecture course. As such, an iCAT may cover one unit, more than one unit, or be comprehensive.

Either at the end of the term only, or at midterm and near the end of the term, students are given the opportunity to provide peer review to the members of their group. If the peer review is complete once during the term, the peer feedback serves primarily as a part of the final grade; if completed twice, the feedback given can be delivered to individuals to help them improve their preparation and team skills. In the latter case, grading for the final peer feedback scores may carry more weight, as it is expected that students will have improved their group skills.

By the time students complete all phases of a TBL course, they have had opportunities for individual assessment through grading of homework required pre-class, individual readiness assessment tests and cumulative assessment tests. Students have experienced team assessment through grading of team readiness assessment tests and any graded activities. And students have received feedback from multiple sources to include the instructor, immediate RAT grading, and peers. The students have also participated in multiple content-related discussions during completion of the tRAT, while engaged in the appeals process, during application activities, and during inter-group discussion in the presentation phase following the completion of activities and choice reporting. All of the elements of TBL collectively result in improved knowledge creation, use of knowledge, and long-term learning (Michaelsen et al., 2004; Michaelsen et al., 2014; Michaelsen \& Sweet, 2008, 2011). 


\section{Conceptual Model for Scholarly Work on TBL in Health Professions Education}

Haidet et al. (2008), considering the characteristics of health professions education that differ from those of the typical higher education classroom setting, proposed a conceptual model in order to provide scholars with a common frame of reference from which to develop research regarding TBL's implementation and evaluation. Haidet's team's stated goal was to make explicit some of the assumptions about TBL and its effects on learning, and to stimulate the process of brainstorming and formulating questions for scholarly work (Haidet et al., 2008. The model places learner engagement at its center, and includes both the individual's engagement with the course materials - in pre-class reading, iRATs, through reflection and study- and the individual's engagement with team members. Within the teams in TBL, group processes work to allow the team to utilize the strengths of each of its members, ultimately increasing team and individual success.

The design decisions of the instructor, also represented in the model, establish the environment in which learner engagement occurs, and has an impact on the quality of learner engagement with course content and with their peers. Also influencing learner engagement are the individual characteristics of the teacher and the learner, the contextual factors such as the physical environment and institutional factors, and the team characteristics. These factors are included as an acknowledgement that multiple mediating dynamics ultimately have some influence on learner engagement. Learning outcomes that TBL should affect, due to its design, are listed and include depth of knowledge, cognitive structures, problem-solving skills, team communication skills, and leadership skills (Haidet et al., 2008). The model will be used to place this study within Haidet's common frame of reference for TBL research. Haidet's model, as adapted by Michaelsen (2008) is presented below (see Figure 4). 


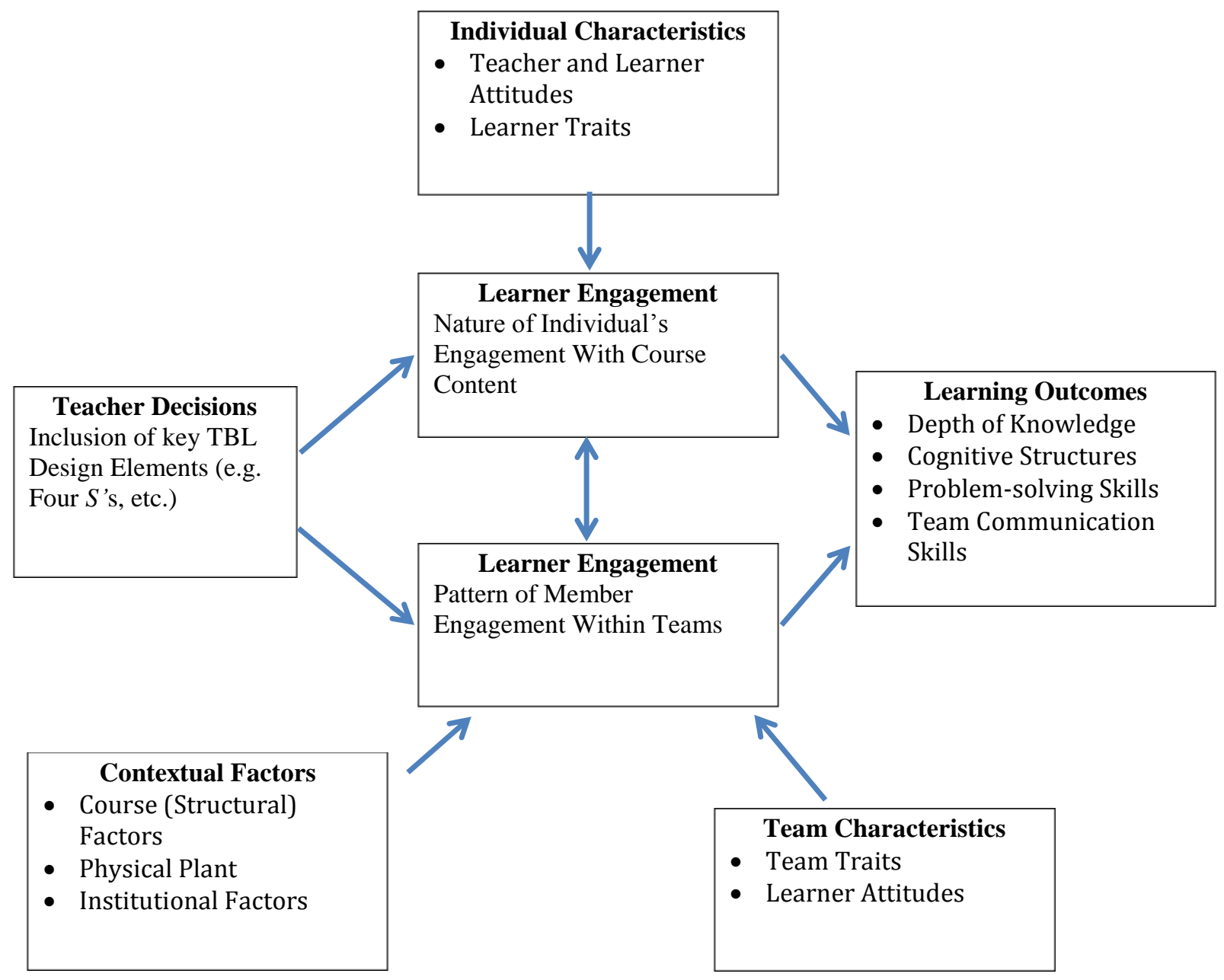

Figure 4 Haidet's Framework for Reporting TBL Research. Reprinted from Team-Based Learning for Health Professional Education (p. 124), by L. K. Michaelsen, D. X. Parmelee, K. K. McMahon, and R. E. Levine (Eds.), 2008, Sterling, VA: Stylus Publishing LLC. Copyright 2008 by Stylus Publishing LLC. Reprinted with permission.

For this study, Haidet's model (Michaelsen, 2008) was used to articulate the individual characteristics of the teacher and the students, the engagement of individuals and teams, the courses' learning outcomes/expectations, the contextual factors relevant to the course presentation, and the team characteristics. This is demonstrated below (see Figure 5): 


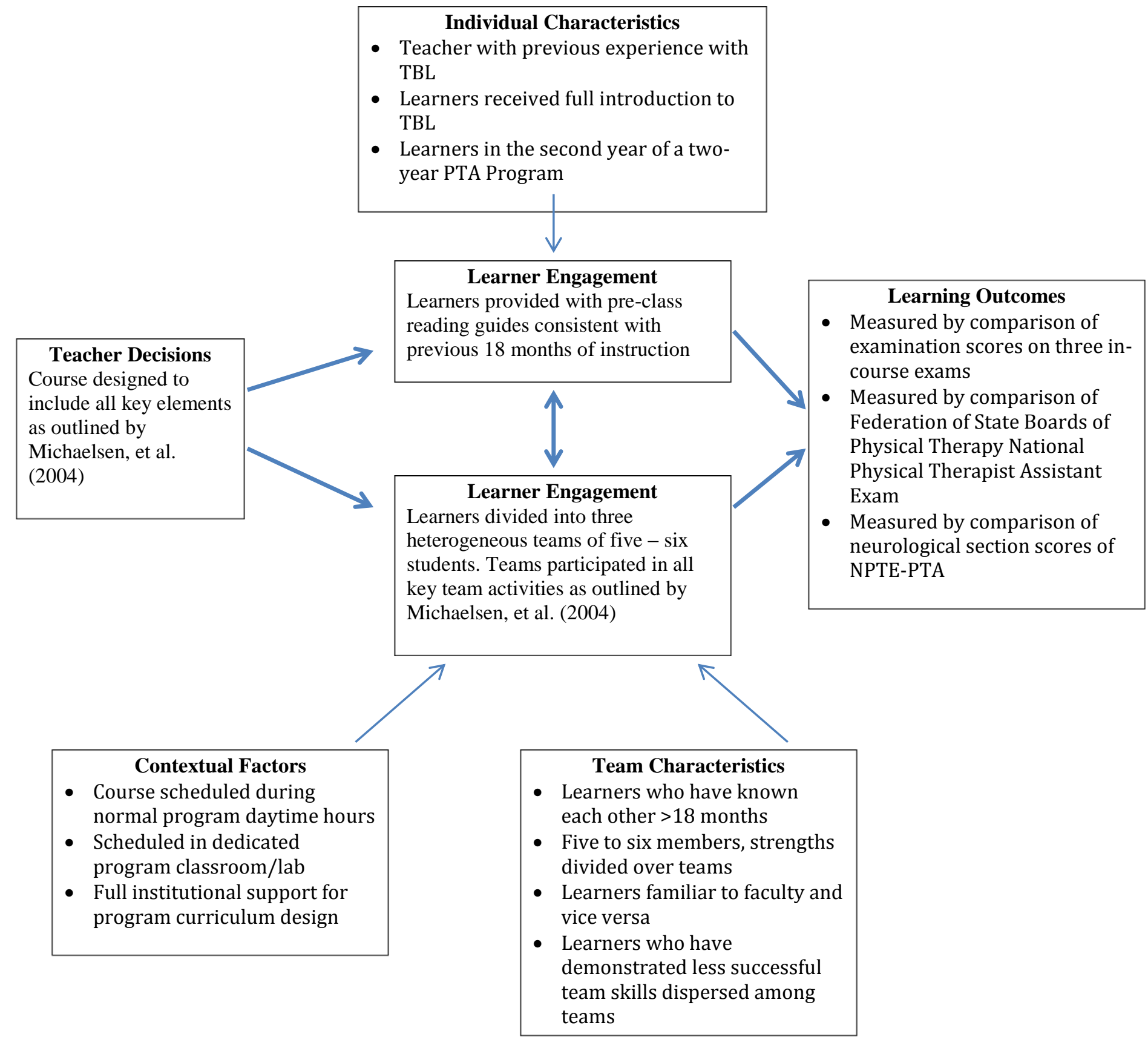

Figure 5 Adapted from Haidet's Framework for Reporting TBL Research. Reprinted from

Team-Based Learning for Health Professional Education (p. 21), by L. K. Michaelsen, D. X.

Parmelee, K. K. McMahon, and R. E. Levine (Eds.), 2008, Sterling, VA: Stylus Publishing LLC.

Copyright 2008 by Stylus Publishing LLC. Adapted with permission. 


\section{Chapter Summary}

Chapter 2 provided an overview of recent literature related to the use of TBL as an instructional strategy in various healthcare educational settings. The review began with evidence related to the issues that institutions and programs face when attrition of students is high, including the loss of "seats" in any given cohort and the inherent costs to the program, institutions, and students themselves. While many reasons for student attrition have been identified, one of the most difficult to alleviate is the loss of students who, in spite of being selected based on cognitive and non-cognitive factors, leave a program for academic reasons.

The theoretical framework that support choosing TBL as an instructional strategy for difficult courses was then presented. Team-based learning courses meet the standards of good practice as outlined by Chickering and Gamson (1997), which are grounded in the learning theories of Vygotsky (1987), Bandura (1986), and Schunk and Zimmerman (1997). Additionally, as an active learning method, TBL encourages self-regulation, intrinsic goal orientation, and increased self-efficacy, as described by Sangestani and Khatiban (2013). Evidence was provided demonstrating the benefits of cooperative and collaborative learning (Janssen, et al., 2010, Prince, 2004), two methods of instruction with which TBL shares many features.

Research related to the use of TBL in healthcare education, to include physician, nursing, pharmacy, and physical therapy education, was reviewed. A discussion regarding the modifications made to the TBL process when studied, to include teaching one or more units of TBL imbedded in a lecture course, utilizing only some of the elements of TBL, or having students attend a portion of a course designed in the TBL format and a second portion designed in a traditional lecture format was presented. Outcomes measured in research on TBL were 
examined; iRAT and tRAT scores, faculty and student satisfaction, and student engagement were found to be the most common. The majority of research completed thus far has demonstrated that TBL does appear to increase student engagement, faculty and student satisfaction, and even team development; however, very little research has focused on student achievement of learning outcomes. This study is significant in that the course studied is considered one of the most difficult courses for students in the studied program, the course was designed and delivered according to all of the elements of the team-based learning model, and learning outcomes were measured during the course and following graduation. The students in the sample for this study were all selected for the physical therapist program based on previously demonstrated academic success, all students took the same exams throughout the courses studied, and a psychometrically similar licensure examination following graduation. 


\section{CHAPTER 3: METHODOLOGY}

\section{Introduction}

The purpose of this chapter is to describe the methodology used to compare the effectiveness of team-based learning with traditional instructor-led lecture based learning for second-year physical therapist assistant students. Chapter 3 presents the research design, research questions and hypotheses, and instrumentation used. Data collection and analysis procedures are also discussed.

\section{Review of The Purpose of The Study}

The purpose of this study was to compare the effectiveness of traditional, instructor-led, lecture-based learning with team-based learning, on learning outcomes, for undergraduate physical therapist assistant students enrolled in a neurorehabilitation course at a small, proprietary college in Middle Tennessee. This study was completed to bridge the gap of research related to the efficacy of TBL as an instructional method for a difficult course, with a relatively homogenous group of students who have demonstrated previous academic success.

\section{Research Questions}

The study is guided by the following research questions:

\section{Research Question 1}

Is there a significant difference in achievement of student learning outcomes as measured by in-class examination scores on four class examinations between second-year physical therapist assistant students who participated in traditional teacher-led, lecture-based learning and second-year physical therapist assistant students who participated in TBL in a second year neurorehabilitation course while controlling for student GPA at the beginning of the course, in a 
two-year integrated physical therapist assistant program based in a small proprietary college in Middle Tennessee?

\section{Research Question 2}

Is there a significant difference in achievement of student learning outcomes as measured by the National Physical Therapy Examination - Physical Therapist Assistant version, between second-year physical therapist assistant students who participated in traditional teacher-led, lecture-based learning and second-year physical therapist assistant students who participated in TBL in a second year neurorehabilitation course in a two-year integrated physical therapist assistant program based in a small proprietary college in Middle Tennessee?

\section{Null Hypothesis}

\section{Null Hypothesis}

There is no statistically significant relationship between the achievement of student learning outcomes between second-year physical therapist assistant students who participated in traditional teacher-led, lecture-based learning and second-year physical therapist assistant students who participated in TBL in a second year neurorehabilitation course in a two-year integrated physical therapist assistant program based in a small proprietary college in Middle Tennessee.

\section{Specific Description of Methodology}

The study design was quantitative where data was collected from course examinations and from the National Physical Therapist Assistant Examination (NPTE-PTA). It was ex post facto as both cohorts have previously completed either the lecture-based course or the TBL course and taken the NPTE-PTA, data was collected from past records. This study was quasiexperimental as the two cohort groups studied were not randomly assigned but instead were a 
part of two second-year cohorts in the same physical therapist assistant program and all students in each year were enrolled in the same course.

\section{Appropriateness of Methodology}

This study used a quantitative, quasi-experimental ex post facto design to examine the effectiveness of team-based learning intervention versus a traditional, instructor-led lecture based teaching method on student learning outcomes measured during the course and following graduation from the PTA program. Quasi-experimental designs include an experimental intervention, but lack the randomization of subjects to control and experimental groups, the hallmark of experimental design (Polit \& Beck, 2014). This study was ex post facto in that the instructor-led control group of students was comprised of students who completed the course in 2013; the team-based learning intervention group was comprised of students who completed the course in 2015. All learning outcome data was collected from the college's learning management system or from reports published previously by the FSBPT. Ex post facto research seeks to: explain a consequence based on antecedent conditions; determine the influence of one variable on another variable, and test a claim using statistical hypothesis testing techniques (Simon \& Goes, 2013). The data used for this study was already collected, but not for the purpose of research. Ex post facto designs have some limitations, to include the lack of random assignment, the potential for inherent confounds in the variables studied, and the dearth of information about dropouts from the study (Cohen, Manion, \& Morrison, 2011). Correlational designs were used to examine how the change in instructional method was associated with changes in learning outcomes. Correlational designs cannot be used to determine causality, but only to identify that a relationship between two variables was statistically 
supported. Efforts to control threats to internal and external validity were used to strengthen this study (LoBiondo-Wood \& Haber, 2013).

\section{Research Design}

This study compared learning outcomes demonstrated by two relatively homogenous groups of physical therapist assistant students after learning through either a lecture-based or a TBL format. One group of seventeen second-year students completed the PTA program's neurorehabilitation course delivered in a traditional lecture format. The second group of sixteen second-year students completed the same course, delivered in a TBL-structured format.

Learning outcomes were measured using examination grades for the four course examinations given during the neurorehabilitation course, and the scores on the Physical Therapist Assistant Examination proctored by the Federation of State Boards of Physical Therapy, taken by both groups of students subsequent to graduation from the program. The following elements of the

study made it unique: TBL methodology was used to design the TBL course exactly as described in Larry Michaelsen's (2004) foundational text; the TBL method was utilized for the delivery of the entire content of the course, as opposed to just units of material; the same faculty member taught both courses; the four examinations were identical for students in both courses, and the National Physical Therapist Assistant Examination (NPTE-PTA), a standardized measure, assessed retention of material months later. Demographic information was available for all students, permitting an analysis of confounding variables.

The study compared examination outcomes of two iterations of the neurorehabilitation course - one that was taught in a traditional lecture format in fall of 2013 , and one that was taught using a TBL format in fall of 2015. The TBL course was piloted during the intervening year, and learning outcomes for the intervening group were utilized to evaluate the content 
validity of the in-course examinations. Issues identified in previous research did not limit this study. Both courses were both taught by the same instructor. The TBL course was presented once as a pilot during the fall 2014 term, so that it could be modified as necessary and so that the instructor/researcher could gain proficiency with delivery using TBL. The TBL course was developed in its entirety according to guidelines outlined by Michaelsen et al. (2004). The traditional lecture design and TBL courses were grounded on key topics required of graduates of a physical therapist assistant program (Commission on Accreditation in Physical Therapy Education, 2016). Seventeen students were enrolled in the lecture-based course in 2013; sixteen students were enrolled in the team-based learning course in 2015.

Students from both courses took identical written and practical lab examinations during their respective courses, and both groups took the National Physical Therapist Assistant Examination (NPTE-PTA). Although the two cohorts took the NPTE-PTA in different years (the first cohort in 2014, and the second cohort in 2016), these examinations are psychometrically similar board examinations, based on the National Physical Therapy Examination - Physical Therapist Assistant version (NPTE-PTA) Test Content Outline, effective January 2013 (Federation of State Boards of Physical Therapy, 2013). Course examination scores for both the lecture and TBL cohorts have been recorded in Canvas, the college's learning management system. NPTE-PTA examination results and content breakdown and scoring were obtained from the Federation of State Boards of Physical Therapy (FSBPT).

\section{Dependent Variables}

Data on two dependent variables were measured. First, written course examination scores for four examinations taken during the neurorehabilitation class were collected. The same four examinations were given to both cohorts of students. The cohort of students who 
participated in the lecture-based course took a course examination every two to three weeks during the quarter. Each written course examination covered two textbook chapters. The cohort of students who participated in the TBL-based course took the same four examinations, at the conclusion of every two TBL units. Team-based learning units were created to coincide with the same textbook chapters as those used for the lecture-based course.

Average cohort group scores on the Neuromuscular and Nervous System questions on the NPTE-PTA in 2014, for the cohort of students who participated in the lecture-based course in 2013, and graduated from the program in 2014. Average cohort group scores on the NPTE-PTA in 2016, for the cohort of students who participated in the TBL-based course in 2015, and graduated from the program in 2016 were collected. Approximately seventy-nine percent of the examination content of the NPTE-PTA is focused on specific body systems. Of the body systems portion of the exam, $81 \%$ percent of the questions are focused on three primary systems: the musculoskeletal; neuromuscular/nervous; and cardiovascular/pulmonary/lymphatic. The other $19 \%$ of the systems-based questions include questions on the integumentary, metabolic and endocrine, gastrointestinal and genitourinary systems (Federation of State Boards of Physical Therapy, 2013; O'Sullivan \& Seigelman, 2013). Examination outcomes are reported to program faculty in three reports - a basic report, a content area report, and a graduate performance report. This study will utilize data reported in the Content Area School Report of the mean scale score achieved by students on the Neuromuscular and Nervous Systems section of the examination.

\section{Independent Variable}

The independent variable will be the instructional method used to teach PTA250 Treatment and Procedures IV - Neurorehabilitation, a course taught in the seventh quarter of an eight-quarter, two-year physical therapist assistant program. For one cohort of students, this 
course was delivered using a traditional, lecture-based format; for the other cohort, this course was delivered using a team-based learning format.

\section{Participants}

Participants included students who were enrolled in the lecture-based course in 2013 and students who were enrolled in the team-based learning course in 2015. Students from both courses took identical written and practical lab examinations during their respective courses, and both groups have taken the National Physical Therapist Assistant Examination (NPTE-PTA). Although the two cohorts took the NPTE-PTA in different years (the first cohort in 2014, and the second cohort in 2016), these board examinations are psychometrically similar, based on the National Physical Therapy Examination - Physical Therapist Assistant version (NPTE-PTA) Test Content Outline, effective January 2013 (Federation of State Boards of Physical Therapy, 2013). No Informed Consent will be required for this study, as the data was in existence prior to the study's development.

\section{Instrumentation}

Examinations used during the courses are instructor-created and have been utilized, updated, and modified over a nine-year period. The examinations are specific to neither course design, but do assess understanding and application of key concepts. Content validity of the course examinations was verified through expert assessment and reliability was obtained by administering the same tests to students in the intervening course. Course examination scores for both the lecture and TBL cohorts have been recorded in Canvas, the college's learning management system. NPTE-PTA examination results and content breakdown and scoring will be obtained from the Federation of State Boards of Physical Therapy (FSBPT). 
The NPTE-PTA is a standardized, national examination that is developed, maintained and administered by the Federation of State Boards of Physical Therapy. FSBPT continually researches and uses the best examination methodology available to ensure validity of the examination. It is written by members of the professional physical therapy community and undergoes rigorous psychometric analysis; the question bank for the exam is updated every five years.

\section{Data Collection Procedures}

Data collection procedures included retrieval of archived student examination scores from the college learning management system. Examination scores were retrieved from fall of 2013 for the lecture-based intervention group, fall of 2014 for the pilot group, and fall of 2015 for the TBL intervention group. All student identification information was removed.

Average scores were collected for the Neuromuscular and Nervous System content of the NPTE-PTA 2014, for the lecture-based intervention group who graduated in that year. The average scores were also collected for the Neuromuscular and Nervous System content of the NPTE-PTA 2016, for the TBL intervention group who graduated in that year.

\section{Method of Data Analysis}

Data analysis was completed utilizing IBM SPSS Statistics® version 25. Analysis of variance (ANCOVA) was used to compare the effect of lecture course design vs. TBL design on student learning outcomes during the course as measured by in-course examinations, and following graduation, as measured by content scores on the NPTE-PTA. Covariates for analysis were gender, age, and race, and GPA prior to the start of the neurorehabilitation course. Demographic characteristics were compared for students in the lecture group and in the TBL group. 


\section{Chapter Summary}

Graduates of physical therapist assistant programs are expected to be entry-level generalists, and that necessarily includes mastery of concepts and their application to patient care. PTA education occurs over a relatively brief period of time, and the methods used to communicate material need to not only be a best fit for the material, but must also prepare students to integrate basic science and clinical information for clinical decision making. TBL has been shown to offer opportunities for students to learn to make decisions and choices within a team environment in the classroom, in preparation for the clinical environment. TBL is comparatively new as an instructional strategy, and there is limited evidence for its efficacy. This study has the potential to add to the understanding of how TBL can be used as a method of teaching material in a physical therapist assistant program, and how it compares to a traditional lecture course delivery in meeting student learning outcomes.

This chapter described the research methodology and data collection procedures utilized in this study. The study used a retrospective quasi-experimental research design. A nonrandomized sample of second-year physical therapist assistant students, from a small proprietary college in Middle Tennessee, served as the population for the study. The instructorled, lecture-based cohort group of seventeen students was enrolled in the neurorehabilitation course in 2014. The team-based learning cohort group of sixteen students was enrolled in the neurorehabilitation course in 2016. All members of both cohort groups were included in the study.

Data collection included retrieval of student course grades, to include grades earned on individual exams during the course, from the college's management learning system, Canvas. Additionally, mean licensure exam scores were retrieved from reports published by the 
Federation of State Boards of Physical Therapy. These examination scores were used as measures of learning outcomes. Data analysis included descriptive and nonparametric statistics for demographic characteristics. Correlational statistics were used to identify relationships between instructional methods and examination scores in both the lecture-based and team-based learning groups. An independent samples $t$-test was utilized to investigate whether NPTE Neuro scores varied as a function of instructional method. 


\section{CHAPTER 4: ANALYSIS OF DATA}

\section{Introduction}

The purpose of this chapter is to present the results of the study, which was designed to compare the effectiveness of team-based learning with traditional, instructor-led learning, as measured by learning outcomes during the course and following graduation from the program. The two instructional methods were utilized for a neurorehabilitation course for second year students in a physical therapist assistant program. The chapter will discuss the methods used to analyze the data and will present results for each research question. The chapter will conclude with a summary of findings.

\section{Explanation of Methodology and Overview of Results}

Data was analyzed using IBM SPSS Statistics® version 25 software. Descriptive statistics were completed to describe the sample characteristics, as well as the means and standard deviations for each examination for all subjects combined and by instructional method. Prior to all statistical analyses, the dataset was restricted to respondents who were either in the lecture group $(n=17)$ or the TBL group $(n=16)$. Inferential statistics were used for testing the differences between the means of the two groups. An ANCOVA was run to determine the effect of instructional methods on learning outcomes as measured by in-course exam scores and NPTE Neuro group averages, after controlling for pre-course GPA. There was a linear relationship between the covariate of pre-course GPA and exam scores for each exam, for each intervention group, as assessed numerically and by visual inspection of a scatterplot. There was homogeneity of regression slopes as the interaction term was not statistically significant. There was homoscedasticity and homogeneity of variances, as assessed by visual inspection of a scatterplot and Levene's test of homogeneity, reported for each dependent variable, below. 


\section{Descriptive Statistics}

The participants for this study consisted of 33 second-year students in two iterations of the neurorehabilitation course in a physical therapist assistant program. Percentages and frequencies were calculated for all categorical variables for the sample in Table 1. Ritchey (2008) notes that for categorical variables, percentages and frequencies are the appropriate descriptive statistics to report. The majority of students were female (78.8\%) and Caucasian $(87.9 \%)$. There were a nearly equal percentage of students in the lecture $(51.5 \%)$ and TBL $(48.5 \%)$ courses.

Table 1 Percentages and Frequencies, Study Variables

\begin{tabular}{lcc}
\hline & Frequency & Percent \\
\hline Gender of Respondent & 7 & \\
$\quad$ Male & 26 & $78.8 \%$ \\
$\quad$ Female & & \\
Race of Respondent & 29 & $87.9 \%$ \\
$\quad$ Caucasian & 3 & $9.1 \%$ \\
$\quad$ African American & 1 & $3.0 \%$ \\
$\quad$ Hispanic/Latino & & \\
Type of Instruction & 17 & $51.5 \%$ \\
$\quad$ Lecture & 16 & $48.5 \%$ \\
$\quad$ TBL & 33 & $100.0 \%$
\end{tabular}

Means and standard deviations were calculated for all continuous variables for the sample in Table 2. Ritchey (2008) notes that for continuous variables, means and standard deviations are the appropriate descriptive statistics to report. The average age for all students was 28 years of age and the average pre-course GPA was 3.48 on a 4.0 scale. The average exam scores for Exams 1 (78.9\%), Exam 2 (79.70\%), and Exam 3 (78.79\%), were slightly below a B. The average Exam 4 score was a B $(80.94 \%)$. The average NPTE Neuro score was 671.20 on an 
800-point scaled score. Means and standard deviations were calculated for each exam by instructional method in Tables 3 through 6. The mean score for Exam 1 was slightly lower for the lecture group (77.24) than that of the TBL group (80.81\%). The mean score for Exam 2 was slightly lower for the lecture group (78.9\%) than for the TBL group $(80.5 \%)$. The mean score for Exam 3 was slightly lower for the lecture group (77.18\%) than for the TBL group (80.5\%). The mean score for Exam 4 was slightly lower for the lecture group (77.94\%) than for the TBL group $(84.12 \%)$.

Table 2

Means and Standard Deviations, Scale Variables

\begin{tabular}{lcc}
\hline \multicolumn{1}{c}{ Variable } & M & SD \\
\hline Age of Respondent & 28.33 & 6.11 \\
Pre-Course GPA & 3.48 & 0.42 \\
Exam 1 Score & 78.97 & 10.96 \\
Exam 2 Score & 79.70 & 8.96 \\
Exam 3 Score & 78.79 & 6.46 \\
Exam 4 Score & 80.94 & 8.21 \\
NPTE Neuro Score & 671.20 & 16.99 \\
\hline
\end{tabular}

Note: $N=33$.

Table 3

Descriptive Statistics for Examination 1 Score by Instruction Method

\begin{tabular}{cccc} 
Variable & $n$ & $M$ & $S D$ \\
\hline Lecture & 17 & 77.24 & 13.79 \\
TBL & 16 & 80.81 & 6.80 \\
\hline
\end{tabular}


Table 4

Descriptive Statistics for Examination 2 Score by Instruction Method

\begin{tabular}{cccc} 
Variable & $n$ & $M$ & $S D$ \\
\hline Lecture & 17 & 78.9 & 9.71 \\
TBL & 16 & 80.5 & 8.33 \\
\hline
\end{tabular}

Table 5

Descriptive Statistics for Examination 3 Score by Instruction Method

$\begin{array}{llll}\text { Variable } & n & M & S D\end{array}$

\begin{tabular}{cccc}
\hline & & & \\
Lecture & 17 & 77.18 & 5.05 \\
TBL & 16 & 80.5 & 7.46 \\
\hline
\end{tabular}

Table 6

Descriptive Statistics for Examination 4 Score by Instruction Method

$\begin{array}{llll}\text { Variable } & n & M & S D\end{array}$

\begin{tabular}{cccc}
\hline & & & \\
Lecture & 17 & 77.94 & 8.02 \\
TBL & 16 & 84.12 & 7.36 \\
\hline
\end{tabular}

\section{Research Questions and Hypotheses}

\section{Research Question 1}

Is there a significant difference in achievement of student learning outcomes as measured by in-class examination scores on four class examinations between second-year physical therapist assistant students who participated in traditional teacher-led, lecture-based learning and second-year physical therapist assistant students who participated in TBL in a second year 
neurorehabilitation course while controlling for student GPA at the beginning of the course, in a two-year integrated physical therapist assistant program based in a small proprietary college in Middle Tennessee?

\section{Research Question 2}

Is there a significant difference in achievement of student learning outcomes as measured by the National Physical Therapy Examination - Physical Therapist Assistant version, between second-year physical therapist assistant students who participated in traditional teacher-led, lecture-based learning and second-year physical therapist assistant students who participated in TBL in a second year neurorehabilitation course in a two-year integrated physical therapist assistant program based in a small proprietary college in Middle Tennessee?

Hypothesis 1. There is a significant difference in achievement of student learning outcomes as measured by in-class examination scores on Exam 1 between second-year physical therapist assistant students who participated in traditional teacher-led, lecture-based learning and second-year physical therapist assistant students who participated in TBL in a second year neurorehabilitation course, while controlling for student GPA at the beginning of the course, in a two-year integrated physical therapist assistant program based in a small proprietary college in Middle Tennessee.

Statistical analysis. A one-way analysis of covariance (ANCOVA) was conducted where the independent variable included a treatment group (TBL) and a control group (Lecture), the dependent variable was Exam 1 scores, and the covariate was pre-course GPA. A preliminary analysis evaluating the homogeneity-of-slopes assumption indicated that the relationship between the covariate and the dependent variable did not differ significantly as a function of the independent variable, $F(1,29)=3.940, M S E=103.299, p=0.057$, partial $\eta 2$ 
$=0.120$. Levene's test for homogeneity of variance was statistically non-significant, $F(1,31)=$ $1.439, \mathrm{p}=0.239$. The ANVOCA was non-significant, $F(1,29)=3.187, M S E=329.200, p=$

0.085. The strength of relationship between the independent variable and the dependent variable was weak as assessed by a partial $\eta 2$, with the independent variable accounting for $9.9 \%$ of the variance in the dependent variable, holding constant GPA scores. The means for the treatment group and control group were adjusted for initial differences: the treatment group mean was 81.455, while the control group mean was 73.664. Follow-up tests of these means were unnecessary given the statistically non-significant ANCOVA results. The results of the ANCOVA suggest that there is no difference in Exam 1 scores between the students taught with lecture and the students taught with TBL when controlling for GPA. There is no evidence to support the hypothesis that there is a significant difference in achievement of student learning outcomes as measured by in-class examination scores on Exam 1 between second-year physical therapist assistant students who participated in traditional teacher-led, lecture-based learning and second-year physical therapist assistant students who participated in TBL in a second year neurorehabilitation course.

Table 7

Analysis of Covariance (ANCOVA) Results for Exam 1

\begin{tabular}{lccccc}
\hline \multicolumn{1}{c}{ Independent Variables } & $d f$ & $M S E$ & $F$ & $p$ & $\begin{array}{c}\text { Partial Eta } \\
\text { Square }\end{array}$ \\
\hline Instruction & 1,29 & 397.890 & 3.852 & 0.059 & 0.117 \\
GPA & 1,29 & 652.258 & 6.314 & 0.018 & 0.179 \\
Instruction * GPA & 1,29 & 329.200 & 3.187 & 0.085 & 0.099 \\
\hline
\end{tabular}

Hypothesis 2. There is a significant difference in achievement of student learning outcomes as measured by in-class examination scores on Exam 2 between second-year physical 
therapist assistant students who participated in traditional teacher-led, lecture-based learning and second-year physical therapist assistant students who participated in TBL in a second year neurorehabilitation course, while controlling for student GPA at the beginning of the course, in a two-year integrated physical therapist assistant program based in a small proprietary college in Middle Tennessee.

Statistical analysis. A one-way analysis of covariance (ANCOVA) was conducted where the independent variable included a treatment group (TBL) and a control group (Lecture), the dependent variable was Exam 2 scores, and the covariate was pre-course GPA. A preliminary analysis evaluating the homogeneity-of-slopes assumption indicated that the relationship between the covariate and the dependent variable did not differ significantly as a function of the independent variable, $F(1,29)=3.717, M S E=59.064, p=0.064$, partial $\eta^{2}$ $=0.114$. Levene's test for homogeneity of variance was statistically non-significant, $F(1,31)=$ $1.987, p=0.169$. The ANVOCA was significant, $F(1,29)=8.456, M S E=499.417, p=0.007$. The strength of relationship between the independent variable and the dependent variable was moderate as assessed by a partial $\eta^{2}$, with the independent variable accounting for $22.6 \%$ of the variance in the dependent variable, holding constant GPA scores. The means for the treatment group and control group were adjusted for initial differences: the treatment group mean was 80.762, while the control group mean was 75.040. Least Significant Difference (LSD) post-hoc tests of these means were not possible given the dichotomous nature of the treatment under investigation. There is support in the data for Hypothesis 2; the results of the ANCOVA suggest that the TBL group scored higher on average on Exam $2(M=80.762)$ than the lecture group $(M$ $=75.040)$. 
Table 8

Analysis of Covariance (ANCOVA) Results for Exam 2

\begin{tabular}{lccccc}
\hline Independent Variables & $d f$ & $M S E$ & $F$ & $p$ & $\begin{array}{c}\text { Partial Eta } \\
\text { Square }\end{array}$ \\
\hline Instruction & 1,29 & 550.987 & 9.329 & 0.005 & 0.243 \\
GPA & 1,29 & 643.452 & 10.894 & 0.003 & 0.273 \\
Instruction * GPA & 1,29 & 499.417 & 8.456 & 0.007 & 0.226 \\
\hline
\end{tabular}

Hypothesis 3. There is a significant difference in achievement of student learning outcomes as measured by in-class examination scores on Exam 3 between second-year physical therapist assistant students who participated in traditional teacher-led, lecture-based learning and second-year physical therapist assistant students who participated in TBL in a second year neurorehabilitation course, while controlling for student GPA at the beginning of the course, in a two-year integrated physical therapist assistant program based in a small proprietary college in Middle Tennessee.

Statistical analysis. A one-way analysis of covariance (ANCOVA) was conducted where the independent variable included a treatment group (TBL) and a control group (Lecture), the dependent variable was Exam 3 scores, and the covariate was pre-course GPA. A preliminary analysis evaluating the homogeneity-of-slopes assumption indicated that the relationship between the covariate and the dependent variable did differ significantly as a function of the independent variable, $F(1,29)=8.254, M S E=31.176, p=0.008$, partial $\eta^{2}$ $=0.222$. Levene's test for homogeneity of variance was statistically non-significant, $F(1,31)=$ 1.926, $p=0.175$. The ANVOCA was non-significant, $F(1,29)=0.003, M S E=0.103, p=0.954$. The strength of relationship between the independent variable and the dependent variable was non-existent as assessed by a partial $\eta^{2}$, with the independent variable accounting for $0.0 \%$ of the 
variance in the dependent variable, holding constant GPA scores. The means for the treatment group and control group were adjusted for initial differences: the treatment group mean was 82.006, while the control group mean was 75.811. Follow-up tests of these means were unnecessary given the statistically non-significant ANCOVA results. No support in the data for Hypothesis 3; the results of the ANCOVA suggest that there is no difference in exam 3 scores between the TBL and the Lecture group when controlling for GPA.

Table 9

Analysis of Covariance (ANCOVA) Results for Exam 3

\begin{tabular}{lccccc}
\hline Independent Variables & $d f$ & $M S E$ & $F$ & $p$ & $\begin{array}{c}\text { Partial Eta } \\
\text { Square }\end{array}$ \\
\hline Instruction & 1,29 & 2.066 & 0.066 & 0.799 & 0.002 \\
GPA & 1,29 & 289.611 & 9.290 & 0.005 & 0.243 \\
Instruction * GPA & 1,29 & 0.103 & 0.003 & 0.954 & 0.000 \\
\hline
\end{tabular}

Hypothesis 4. There is a significant difference in achievement of student learning outcomes as measured by in-class examination scores on Exam 4 between second-year physical therapist assistant students who participated in traditional teacher-led, lecture-based learning and second-year physical therapist assistant students who participated in TBL in a second year neurorehabilitation course, while controlling for student GPA at the beginning of the course, in a two-year integrated physical therapist assistant program based in a small proprietary college in Middle Tennessee.

Statistical analysis. A one-way analysis of covariance (ANCOVA) was conducted where the independent variable included a treatment group (TBL) and a control group (Lecture), the dependent variable was Exam 4 scores, and the covariate was pre-course GPA. A preliminary analysis evaluating the homogeneity-of-slopes assumption indicated that the 
relationship between the covariate and the dependent variable did differ significantly as a function of the independent variable, $F(1,29)=18.554, M S E=40.072, p<0.001$, partial $\eta 2$ $=0.390$. Levene's test for homogeneity of variance was statistically non-significant, $F(1,31)=$ $0.411, \mathrm{p}=0.526$. The ANCOVA was non-significant, $F(1,29)=2.555, M S E=102.401, p=$ 0.121. The strength of relationship between the independent variable and the dependent variable was weak as assessed by a partial $\eta 2$, with the independent variable accounting for $8.1 \%$ of the variance in the dependent variable, holding constant GPA scores. The means for the treatment group and control group were adjusted for initial differences: the treatment group mean was 85.512, while the control group mean was 74.981. Follow-up tests of these means were unnecessary given the statistically non-significant ANCOVA results. There was no support in the data for Hypothesis 4; the results of the ANCOVA suggest that there is no difference in exam 4 scores between the TBL and the Lecture group when controlling for GPA.

Table 10

Analysis of Covariance (ANCOVA) Results for Exam 4

\begin{tabular}{lccccc}
\hline Independent Variables & $d f$ & $M S E$ & $F$ & $p$ & $\begin{array}{c}\text { Partial Eta } \\
\text { Square }\end{array}$ \\
\hline Instruction & 1,29 & 165.749 & 4.136 & 0.051 & 0.125 \\
GPA & 1,29 & 680.342 & 16.978 & 0.000 & 0.369 \\
Instruction * GPA & 1,29 & 102.401 & 2.555 & 0.121 & 0.081 \\
\hline
\end{tabular}

Hypothesis 5. There is a significant difference in achievement of student learning outcomes as measured by NPTE-PTA Neuromuscular and Nervous System scores between second-year physical therapist assistant students who participated in traditional teacher-led, lecture-based learning and second-year physical therapist assistant students who participated in TBL in a second year neurorehabilitation course, while controlling for student GPA at 
graduation, age, gender, and race, in a two-year integrated physical therapist assistant program based in a small proprietary college in Middle Tennessee.

Statistical analysis. To investigate whether NPTE Neuro scores varied as a function of TBL versus Lecture, an Independent Samples $t$-Test was hand calculated. This hand calculation was done because the data was in aggregate form. As such, a hand calculation was the only way to investigate if statistically significant differences existed within the data. As Ritchey (2008) notes, the use of an Independent Samples $t$-Test is appropriate when the dependent variable is continuous in nature and the independent variable is a dichotomous nominal-level discrete variable. These criteria are satisfied under the current circumstances. With respect to NPTE Neuro scores, no statistically significant difference was found in the data $(t=1.315 ; d f=14 ; p=$ 0.198). Thus, the mean of the Lecture group $(M=686.9)$ is not statistically different from the mean of the TBL group $(M=659.6)$. There is no support in the data for Hypothesis 5; the results of the $t$-Test suggest that there is no difference in NPTE Neuro scores between the TBL and the Lecture group.

\section{Chapter Summary}

This chapter reported the findings of the data analysis for this study. Although students in the TBL course did average slightly higher on all exams, generally, the results of the retrospective analysis of exam scores and NPTE-PTA scores indicated that the null hypothesis was true for the majority of outcomes analyzed: there was no significant difference in Exam scores between lecture and TBL as an instructional strategy for second-year physical therapist assistant students in a neurorehabilitation course. There is support in the data for Hypothesis 2; the results of the ANCOVA suggest that the TBL group scored higher on average on Exam 2. A 
discussion of these findings, with the conclusions, limitations, and recommendations for future research will be presented in the next chapter. 


\section{CHAPTER 5: SUMMARY, CONCLUSIONS, AND RECOMMENDATIONS}

\section{Introduction}

Summary of The Study's Results

Strengths and Limitations

Recommendations for Future Research

Implications for Health Sciences Education

Chapter Summary 


\section{References}

Academy of Neurologic Physical Therapy. (2015). Compendium for teaching professional level physical therapy content. Education. 2016. Retrieved from http://www.neuropt.org/education

Allen, R. E., Copeland, J., Franks, A. S., Karimi, R., \& McCollum, M. (2013). Team-based learning in US colleges and schools of pharmacy. American Journal of Pharmaceutical Education, 77(6).

Altintas, L., Altintas, O., \& Caglar, Y. (2014). Modified use of team-based learning in an ophthalmology course for fifth-year medical students. Advances in Physiology Education, 38(1), 46-48. doi:10.1152/advan.00129.2013

American Physical Therapy Association. (2015a, October 2015). 2014-2015 Fact sheet physical therapist assistant education programs. Retrieved from http://www.capteonline.org/uploadedFiles/CAPTEorg/About_CAPTE/Resources/Aggreg ate_Program_Data/AggregateProgramData_PTAPrograms.pdf

American Physical Therapy Association. (2015b). Physical therapist assistant (PTA) education overview. Retrieved from http://www.apta.org/PTAEducation/ Overview/

Anderson, J. T. (2012). The challenges and principles of teaching clinical neuroscience. Practical Neurology, 12(6), 345.

Anwar, K., Shaikh, A. A., Sajid, M. R., Cahusac, P., Alarifi, N. A., \& Al Shedoukhy, A. A. (2015). Tackling student neurophobia in neurosciences block with team-based learning. Medical Education Online, 20, 28461. doi:10.3402/ meo.v20.28461 
Ascend Learning LLC. (2012). Student attrition: Consequences, contributing factors, and remedies. Retrieved from http://www.atitesting.com/libraries/pdf/ attrition_whitepaper_ati_2.sflb.ashx

Bandura, A. (1977). Social learning theory. Englewood Cliffs, NJ: Prentice Hall.

Bandura, A. (1986). Social foundations of thought and action: A social cognitive theory. Englewood Cliffs, NJ: Prentice Hall.

Bandura, A. (2005). The evolution of social cognitive theory. In K. Smith \& M. Hitt (Eds.), Great Minds in Management: The Process of Theory Development (pp.10-35). Retrieved from https://www.uky.edu/ eushe2/Bandura/ Bandura2005.pdf

Bleske, B. E., Remington, T. L., Wells, T. D., Dorsch, M. P., Guthrie, S. K., Stumpf, J. L., . . Tingen, J. M. (2014). Team-based learning to improve learning outcomes in a therapeutics course sequence. American Journal of Pharmaceutical Education, 78(1), 15.

Borkowski, J., Carr, M., Rellinger, E., \& Pressley, M. (1990). Self-regulated cognition: Interdependence of metacognition, attributions, and self-esteem (B. F. Jones \& L. Idol Eds.). Hillsdale, NJ: Lawrence Erlbaum.

Brandler, T. C., Laser, J., Williamson, A. K., Louie, J., \& Esposito, M. J. (2014). Team-based learning in a pathology residency training program. American Journal of Clinical Pathology, 142(1), 23-28. doi:10.1309/AJCPB8T1DZKCMWUT

Breneiser, J. E., Monetti, D. M., \& Adams, K. S. (2012). The Nexus between the above-average effect and cooperative learning in the classroom. Educational Research Quarterly, December 2012, 42-61. 
Burgess, A. W., Ayton, T., \& Mellis, C. M. (2016). Implementation of team-based learning in year 1 of a PBL based medical program: a pilot study. BioMedical Central Medical Education, 16(1), 49. doi:10.1186/s12909-016-0550-3

Burgess, A. W., McGregor, D. M., \& Mellis, C. M. (2014). Applying established guidelines to team-based learning programs in medical schools: a systematic review. Academic Medicine, 89(4), 678-688. doi:10.1097/ACM.0000000000 000162

Cheng, C.-Y., Liou, S.-R., Tsai, H.-M., \& Chang, C.-H. (2014). The effects of team-based learning on learning behaviors in the maternal-child nursing course. Nurse Education Today, 34(1), 25-30. doi:10.1016/j.nedt.2013.03.013

Cheong, C. (2010). From group-based learning to cooperative learning: A metacognitive approach to project-based group supervision. Informing Science: the International Journal of an Emerging Transdiscipline, 13, 73-85.

Chickering, A. W., \& Gamson, Z. F. (1987). Seven principles for good practice in undergraduate education. Washington Center News, Fall. Retrieved from http://www.lonestar.edu/multimedia/sevenprinciples.pdf

Chung, H.-M., \& Jackson Behan, K. (2010). Peer sharing facilitates the effect of inquiry-based projects on science learning. The American Biology Teacher, 72(1), 24-29.

Clark, M. C., Nguyen, H. T., Bray, C., \& Levine, R. E. (2008). Team-based learning in an undergraduate nursing course. Journal of Nursing Education, 47(3), 111-117.

Clements, A. J., Kinman, G., Leggetter, S., Teoh, K., \& Guppy, A. (2016). Exploring commitment, professional identity, and support for student nurses. Nurse Education in Practice, 16(1), 20-26. doi:10.1016/j.nepr.2015.06.001 
Cohen, L., Manion, L., \& Morrison, K. (2011). Research Methods in Education (7th ed.). New York, NY: Routledge.

Commission on Accreditation in Physical Therapy Education. (2016). PTA standards and evidence. Retrieved from http://www.capteonline.org/uploadedFiles/ CAPTEorg/About_CAPTE/Resources/Accreditation_Handbook/CAPTE_PTAStandards Evidence.pdf

Currey, J., Oldland, E., Considine, J., Glanville, D., \& Story, I. (2015). Evaluation of postgraduate critical care nursing students' attitudes to, and engagement with, team-based learning: a descriptive study. Intensive and Critical Care Nursing, 31(1), 19-28. doi:10.1016/j.iccn.2014.09.003

Davidson, N., Howell Major, C., \& Michaelson, L. K. (2014). Small group learning in higher education - cooperative, collaborative, problem based and team based learning: An introduction by the guest editors. Journal on Excellence in College Teaching, 25(3 \& 4), $1-6$.

Desmarais, L., Woble-Valenski, M., \& Oestmann, E. (2011). Factors influencing physical therapist assistant licensure examination success. Journal of Physical Therapy Education, 25(2), 36-41.

Elberson, K. L., Vance, A. R., Stephenson, N. L., \& Corbett, R. W. (2001). Teaching strategies cooperative learning: A strategy for teaching pathophysiology to undergraduate nursing Students. Nurse Educator, 26(6), 259-261.

Eng, T. T. (2009). Exploring cooperative learning in out of class academic collaboration to promote active learning among nurses at the clinical area. Singapore Nursing Journal, $36(3), 7-11$. 
Fatmi, M., Hartling, L., Hillier, T., Campbell, S., \& Oswald, A. E. (2013). The effectiveness of team-based learning on learning outcomes in health professions education: BEME Guide No. 30. Medical Teacher, 35(12), 1608-1624. doi:10.3109/0142159X.2013.849802

Federation of State Boards of Physical Therapy. (2013). NPTE-PTA Test Content Outline. Retrieved from https://www.fsbpt.org/Portals/0/documents/freeresources/ContentOutline_2013PTA_201212.pdf

Flanagan, E., Walsh, C., \& Tubridy, N. (2007). 'Neurophobia' - attitudes of medical students and doctors in Ireland to neurological teaching. European Journal of Neurology, 14(10), 1109-1112. doi:10.1111/j.1468-1331.2007.01911.x

Galetta, S. L., Jozefowicz, R. F., \& Avitzur, O. (2006). Advances in neurological education: a time to share. Annals of Neurology, 59(4), 583-590. doi:10.1002/ana.20835

Griffith, S. C. (1990). Cooperative learning techniques in the classroom. Journal of Experiential Education, 13(2), 41-44. doi:10.1177/105382599001300208

Griswold, C. M. (2014). Understanding causes of attrition of 1st-and 2nd-year nursing students. (Doctor of Education Dissertation), Walden University.

Haidet, P., Kubitz, K., \& McCormack, W. T. (2014). Analysis of the team-based learning literature: TBL comes of age. Journal on Excellence in College Teaching, 25(3 \& 4), 303-333.

Haidet, P., Levine, R. E., Parmelee, D. X., Crow, S., Kennedy, F., Kelly, P. A., . . Richards, B. F. (2012). Perspective: Guidelines for reporting team-based learning activities in the medical and health sciences education literature. Academic Medicine, 87(3), 292-299. doi:10.1097/ACM.0b013e318244759e 
Haidet, P., Schneider, V., \& Onady, G. M. (2008). Research and scholarship: Team-based learning in health professions education. In L. Michaelsen, D. Parmelee, K. K. McMahon, \& R. E. Levine (Eds.), Team-Based Learning for Health Professional Education: A Guide to Using Small Groups for Improving Learning (pp. 117-130). Sterling, VA: Stylus.

Hake, R. (1998). Interactive-engagement vs. traditional methods: A six-thousand-student survey of mechanics test data for introductory physics courses. American Journal of Physics, 66(1).

Hamshire, C., Willgoss, T. G., \& Wibberley, C. (2012). 'The placement was probably the tipping point' - the narratives of recently discontinued students. Nurse Education in Practice, 12(4), 182-186. doi:10.1016/j.nepr.2011.11.004

Harmon, R. B., \& Hills, R. L. (2015). Transforming psychiatric mental health nursing education with team based learning. Archives of Psychiatric Nursing, 29(6), 413-418. doi:10.1016/j.apnu.2015.06.014

Hashmi, N. R. (2014). Team based learning (TBL) in undergraduate medical education. Journal of the College of Physicians and Surgeons Pakistan, 24(8).

Hazard Munro, B. (2004). Statistical Methods (5th ed.). Philadelphia, PA: Lippincott Williams \& Wilkins.

Hrynchak, P., \& Batty, H. (2012). The educational theory basis of team-based learning. Medical Teacher, 34, 796-801.

Humbert, K. A., \& Chang, B. S. (2014). In the beginning: How medical students choose (or do not choose) neurology. Annals of Neurology, 75(4), 487-489. doi:10.1002/ana.24133 
Janssen, J., Kirschner, F., Erkens, G., Kirschner, P. A., \& Paas, F. (2010). Making the black box of collaborative learning transparent: combining process-oriented and cognitive load approaches. Educational Psychology Review, 22(2), 139-154. doi:10.1007/s10648-0109131-x

Johnson, D. W., Johnson, R. T., \& Smith, K. A. (2014). Cooperative learning: Improving university instruction by practice on validated theory. Journal on Excellence in College Teaching, 25(3 \& 4), 85-118.

Koles, P., Nelson, S., Stolfi, A., Parmelee, D., \& Destephen, D. (2005). Active learning in a year 2 pathology curriculum. Medical Education, 39(10), 1045-1055. doi:10.1111/j.13652929.2005.02248.x

Ku, H.-Y., Tseng, H. W., \& Akarasriworn, C. (2013). Collaboration factors, teamwork satisfaction, and student attitudes toward online collaborative learning. Computers in Human Behavior, 29(3), 922-929. doi:10.1016/j.chb.2012.12.019

Laerd Statistics. (2015). One-was ANCOVA using SPSS statistics. Statistical tutorials and software guides. Retrieved from https://statistics.laerd.com/

Livingston, B., Lundy, M., \& Harrington, S. (2014). Physical therapy students' perceptions of team-based learning in gross anatomy using the Team-Based Learning Student Assessment Instrument. Journal of Educational Evaluation for Health Professions, 11, 1. doi:10.3352/jeehp.2014.11.1

LoBiondo-Wood, G., \& Haber, J. (2013). Nursing Research: Methods and critical appraisal for evidence-based practice. St. Louis, MO: Elsevier. 
Lou, Y., Abrami, P. C., Spence, J. C., Poulsen, C., Chambers, B., \& d'Applonia, S. (1996). Within-class grouping: A meta-analysis. Review of Educational Research, 66(4), 423458.

Lukas, R. V., Cooper, B., Morgan, I., Brorson, J. R., Dong, H., \& Sherer, R. (2014). Attitudes toward neurosciences in medical students in Wuhan, China: A survey study. World Neurosurgery, 266-269.

Lunstroth, R. B., E. (2014). Teaching big in Texas: team-based learning for professionalism education in medical schools. American Medical Association Journal of Ethics, 16(9), 718-721.

Maranhao-Filho, P. (2014). The healthy concern to improve neurological teachings. Arquivos de Neuro-Psiquiatria, 72(10), 743-744.

Maring, J., Costello, E., Uffer, M., \& Zuber, E. (2016). Curriculum, faculty, and cohort variables predicting physical therapist assistant program graduate success on the national physical therapy examination. Journal of Physical Therapy Education, 27(2), 33-40.

Maslakpak, M. H., Parizad, N., \& Zareie, F. (2015). The impact of team-based learning on nervous system examination knowledge of nursing students. Journal of Caring Science, 4(4), 331-339. doi:10.15171/jcs.2015.033

McColgan, P., McKeown, P. P., Selai, C., Doherty-Allan, R., \& McCarron, M. O. (2013). Educational interventions in neurology: a comprehensive systematic review. European Journal of Neurology, 20(7), 1006-1016. doi:10.1111/ ene.12144

McMullen, I., Carledge, J., Levine, R., \& Iversen, A. (2013). Team-based learning for psychiatry residents: A mixed method study. BioMedical Central Medical Education, 13(124). 
Mennenga, H. (2010). Team-Based Learning: Engagement and Accountability with Psychometric Analysis of a New Instrument. (Doctor of Philosophy in Nursing), University of Nevada, Las Vegas, Nevada, Las Vegas. (3423775)

Mennenga, H. A. (2013). Student engagement and examination performance in a team-based learning course. Journal of Nursing Education, 52(8), 475-479. doi:10.3928/0148483420130718-04

Michaelsen, L. K., Bauman Knight, A., \& Fink, L. D. (2004). Team-Based Learning: A Transformative Use of Small Groups in College Teaching. Sterling, VA: Stylus.

Michaelsen, L. K., Davidson, N., \& Howell Major, C. (2014). Team-based learning practices and principles in comparison with cooperative learning and problem-based learning. Journal on Excellence in College Teaching, $25(3$ \& 4), 57-84.

Michaelsen, L. K., Parmelee, D. X., McMahon, K. K., \& Levine, R. E. (Eds.). (2008). TeamBased Learning for Health Professions Education (1st ed.). Sterling, VA: Stylus.

Michaelsen, L. K., \& Sweet, M. (2008). The essential elements of team-based learning. New Directions for Teaching and Learning, 2008(116), 7-27. doi:10.1002/tl.330

Michaelsen, L. K., \& Sweet, M. (2011). Team-based learning. New Directions for Teaching and Learning, 2011(128), 41-51. doi:10.1002/t1.467

Mody, S. K., Kiley, J., Gawron, L., Garcia, P., \& Hammond, C. (2013). Team-based learning: a novel approach to medical student education in family planning. Contraception, $88(2)$, 239-242. doi:10.1016/j.contraception.2012.07.012

O'Sullivan, S. B., \& Seigelman, R. P. (2013). PTA examination review and study guide (K. E. Ryan \& B. McKnight Eds. 4 ed.). Evanstone, IL: International Educational Resources. 
Ofstad, W., \& Brunner, L. J. (2013). Team-based learning in pharmacy education. American Journal of Pharmaceutical Education, 77(4), 1-12.

Oxford, R. L. (1997). Cooperative learning, collaborative learning, and interaction: Three communicative strands in the language classroom. The Modern Language Journal, 81(4), 443-456.

Polit, D. F., \& Beck, C. T. (2014). Essentials of nursing research: appraising evidence for nursing practice (8th ed.). Philadephia, PA: Wolters Kluwer/Lippincott/ Williams \& Wilkins Health.

Prince, M. (2004). Does active learning work? A review of the research. Journal of Engineering Education, 93(3), 223-231.

Punja, D., Kalludi, S. N., Pai, K. M., Rao, R. K., \& Dhar, M. (2014). Team-based learning as a teaching strategy for first-year medical students. Australasian Medical Journal, 7(12), 490-499. doi:10.4066/AMJ.2014.2244

Rathner, J. A., \& Byrne, G. (2014). The use of team-based, guided inquiry learning to overcome educational disadvantages in learning human physiology: a structural equation model. Advances in Physiology Education, 38(3), 221-228. doi:10.1152/advan.00131.2013

Roh, Y. S., Lee, S. J., \& Mennenga, H. A. (2014). Factors influencing learner satisfaction with team-based learning among nursing students. Nursing and Health Sciences, 16(4), 490497. doi:10.1111/nhs. 12118

Ruckert, E., McDonald, P. L., Birkmeier, M., Walker, B., Cotton, L., Lyons, L. B., .. . Plack, M. M. (2014). Using technology to promote active and social learning experiences in health professions education. Online Learning, 18(4), 1-22. 
Sanderson, T. R. (2014). Relating admissions criteria to dental hygiene student retention. Journal of Allied Health, 43(4), 235-240.

Sangestani, G., \& Khatiban, M. (2013). Comparison of problem-based learning and lecturebased learning in midwifery. Nurse Education Today, 33(8), 791-795.

Saudek, K., \& Treat, R. (2015). Team-based learning on a third-year pediatric clerkship improves NBME subject exam blood disorder scores. Medical Education Online, 20, 29021. doi:10.3402/meo.v20.29021

Schneider, M., \& Yin, L. (2011). The hidden costs of community colleges. American Institutes for Research. Retrieved from http://www.air.org/sites/default/files/ downloads/report/AIR_Hidden_Costs_of_Community_Colleges_Oct2011_0.pdf

Schunk, D. H., \& Zimmerman, B. J. (1997). Social Origins of Self-Regulatory Competence. Educational Psychologist, 32, 195-208.

Simon, M. K., \& Goes, J. (2013). Ex Post Facto Research. Dissertation Success. Retrieved from http://www.dissertationrecipes.com/wp-content/uploads/ 2011/04/Ex-Post-Factoresearch.pdf

Sisk, R. J. (2011). Team-based learning: systematic research review. Journal of Nursing Education, 50(12), 665-669. doi:10.3928/01484834-20111017-01

Springer, L., Stanne, M., \& Donovan, S. (1999). Effects of small-group learning on undergraduates in science, mathematics, engineering and technology: A meta-analysis. Review of Educational Research, 69(1), 21-52.

Sungur, S., \& Tekkaya, C. (2006). Effects of problem-based learning and traditional instruction on self-regulated learning. The Journal of Educational Research, 99(5), 307-317. 
Tan, N. C., Kandiah, N., Chan, Y. H., Umapathi, T., Lee, S. H., \& Tan, K. (2011). A controlled study of team-based learning for undergraduate clinical neurology education. BioMedical Central Medical Education, 11, 91. doi:10.1186/1472-6920-11-91

Thomas, J. R., Silverman, S., \& Nelson, J. (2015). Research Methods in Physical Activity (7th ed.). Champaign, IL: Human Kinetics.

Thomas, P. A., \& Bowen, C. W. (2011). A controlled trial of team-based learning in an ambulatory medicine clerkship for medical students. Teaching and Learning in Medicine, 23(1), 31-36. doi:10.1080/10401334.2011.536888

Thompson, B. M., Haidet, P., Borges, N. J., Carchedi, L. R., Roman, B. J., Townsend, M. H., . . Levine, R. E. (2015). Team cohesiveness, team size and team performance in team-based learning teams. Medical Education, 49(4), 379-385. doi:10.1111/medu.12636

Thompson, B. M., Schneider, V. F., Haidet, P., Levine, R. E., McMahon, K. K., Perkowski, L. C., \& Richards, B. F. (2007). Team-based learning at ten medical schools: two years later. Medical Education, 41(3), 250-257. doi:10.1111/j.1365-2929.2006.02684.x

Vanderzalm, J., Hall, M. D., McFarlane, L.-A. A., Rutherford, L., \& Patterson, S. K. (2013). Fostering interprofessional learning in a rehabilitation setting: development of an interprofessional clinical learning unit. Rehabilitation Nursing, 38(4), 178-185. doi:10.1002/rnj.78

Vygotsky, L. S. (1987). The collected works of L. S. Vygotsky. New York, NY: Plenum Press. Weiner, H., Plass, H., \& Marz, R. (2009). Team-based learning in intensive course format for first-year medical students. Croatian Medical Journal, 50(1).

Wells, M. (2007). Dreams deferred but not deterred: a qualitative study on undergraduate nursing student attrition. Journal of College Student Retention, 8(4), 439-456. 
Yang, L.-H., Jiang, L.-Y., Xu, B., Liu, S.-Q., \& Liang, Y.-R. (2014). Evaluating team-based, lecture-based, and hybrid learning methods for neurology clerkship in China: a methodcomparison study. BioMedical Central Medical Education, 14, 98. doi:10.1186/14726920-14-98

Youssef, F. F. (2009). Neurophobia and its implications: evidence from a Caribbean medical school. BMC Medical Education, 9, 39. doi:10.1186/1472-6920-9-39

Zaidi, S., \& Nasir, M. (2014). Teaching and Learning Methods in Medicine. New York, NY: Springer.

Zimmerman, B. J. (1990). Self-regulated learning and academic achievement: An overview. Educational Psychologist, 25(1), 3-17.

Zinchuk, A. V., Flanagan, E. P., Tubridy, N. J., Miller, W. A., \& McCullough, L. D. (2010). Attitudes of us medical trainees towards neurology education: "Neurophobia" - a global issue. BMC Medical Education, 10(49). doi:10.1186/1472-6920-10-49 


\section{APPENDIX A: Sample Pre-Course Reading Guide}

PTA250 Unit 2.1 Reading Guide - IFO Ch. 2

I hesitate to separate your reading into separate reading guides because I know that the topics in the IFO text and in the Martin \& Kessler text overlap, but I'm going to do it so that the workload is manageable. But please keep in mind that there is overlap here, even though your IFO text is about rehabilitation, and that primarily of adults, and the Martin \& Kessler text is about development. In spite of that, these very different authors are really talking about the same thing. Since the IFO text is about rehabilitation - and remember that this term means re-learning, it is applying developmental principles to adult treatment.

At any rate, we are going to start in the IFO text. Please start reading on page 14. Your text introduces a couple of different neurorehabilitation techniques in this chapter, but don't miss the sentence on page 14 that says that no one treatment is a perfect fit for all patients, or for any one patient throughout his/her rehabilitation. In fact, studies have shown that neuro PTs use lots of different techniques bundled together, with very little consistency. Neuro PT is far more about the individual patient than it is any technique. So it's okay to really buy into one or another method, just don't get so attached that you're inflexible. It's important to note as well, that your text distinguishes between augmented intervention and compensatory intervention. To break these down: augmented intervention is the traditional treatment used with neurologically involved patients (let's make up a new acronym, shall we? From now on, these are NIPs). For instance, NDT has at its root the philosophy that correct movement can be guided (augmented) by a skilled therapist, and that with appropriate facilitation and inhibition, a NIP can learn or relearn motor control. We would use guided movement with any patient that has recovery potential.

On the other hand, we might choose to use compensatory intervention strategies with a patient who has limited recovery potential, such as a patient with a SCI. This patient is unlikely to recover function below the level of injury; consequently, augmented intervention would be a waste of time. Better to spend that time teaching the patient compensatory movements so that he/she can be functional within the constraints of his/her new limitations.

Finally, impairment-specific interventions are those that are geared toward treating impairments. While it's true that some impairments need to be addressed so that a patient's function can be improved, that should be the only reason for treating an impairment. It's much more important to treat at the level of functional limitation or disability. 
Beginning on page 14, under the heading "Task Analysis", there is a discussion regarding what it means to break down activities into individual steps. We've talked a lot previously about how important it is that the goals set in physical therapy are as important to the patient as they are to the therapist. Task analysis is the process whereby we take the goals that we have set for a patient and we break them down into component parts. Analysis of those component parts should inform us as to what it is the patient is, or is not, able to do that is limiting task accomplishment. Your textbook flies over this section pretty quickly, so I want to guide your attention to page 16, Box 2.2. This box is inclusive of all of the different questions that a therapist might ask in order to determine what parts of the task are difficult for a patient, and how those difficulties may be keeping him from completing the task. Note in this box, under the heading "What are the normal requirements?" that the therapist may need to think about what the motor control requirements of the activity are. Those motor requirements might be mobility, stability, dynamic or controlled mobility, or skill. I know that this text uses different terms from the Martin text; please don't let that confuse you. Controlled mobility and dynamic stability are different, but only insofar as one allows for movement of the proximal segment, and one does not. Which one is which, do you think?

Before you go on, be sure to relate this section of the text with Figure 1.1 on page 4. Task analysis requires assessment of the three elements inherent in any task: the task itself, the individual performing it, and the environment in which it is performed. Seriously, think about this. Any component of any one of these three elements is a potential assister or limiter for the patient.

Now we may or may not have already discussed what mobility, stability, controlled mobility, and skill look like in the adult. I hope that we have. In case we haven't, please remember that mobility for the infant is random movements, without any direction or control. Mobility for an adult is available range of motion or degrees of freedom, especially as they relate to initiating, controlling, and terminating movement. Stability in both infants and adult is the same - the ability to co-contract and maintain static postural control. Controlled mobility in both infants and adult is also the same. That is, the ability to weight shift within a base of support without losing one's balance. Dynamic stability implies that an individual is able to weight shift and use his upper extremities to perform activity without losing balance, and that he stays within his COS. And skill, of course, is everything that you do that requires dynamic control imposed on core stability.

I know that Box 2.2 has a lot in it. But it's important to read through it and see how the physical therapist was thinking when she initially designed the plan of care. You, as PTAs are expected to be able to figure out what it is that is stopping the patient from performing a specific task. Sometimes he is missing the ability to initiate movement; sometimes he simply doesn't have the motor sequence, or motor plan available. Sometimes the patient can't terminate or control 
motion and sometimes there is a strength or range of motion limitation. And sometimes movement is delayed or timing and sequencing is inconsistent with the task. Or perhaps the task is too difficult, or the environment is too noisy. If we do not do an appropriate task analysis, we run the risk of becoming the type of therapists who are always treating for range of motion and strength limitations. For most NIPs, range of motion and strength are only two very small parts of a complex condition.

Before we go on, I want you to be sure to read the last paragraph on page 16 carefully. This is about variability and how we, as therapists, need to treat in order to improve variation and variability. I'm going to talk about this a lot, so bear with me. Let's consider that you could decide that a NIP needs to learn to perform a sit to stand transfer. You could choose to have the patient sit to stand from the mat with TCs and VCs until he gets it right. Or you could set up the environment so that the patient needs to stand to reach an object on a counter, and you could make that object light, heavy, oddly shaped, etc. from one trial to the next. You could change the height of the chair that the patient is standing from, or use a wheelchair, or a walker bench. You could set up the environment and let the patient solve for a motor plan that works. The latter is likely to increase the patient's variation of responses, consequently building his variability. The latter is good therapy.

Page 17, box 2.3, presents you with a long list of functional, task-oriented training strategies. I don't expect that you will memorize all of these now. However, I do want you to remember that this is box here so that you know to go back and look for ideas when you get into a training rut or when what you are doing just doesn't seem to be working. For quick and easy practice, think about treating a four-year old with cerebral palsy. We've been working on transitioning from half-kneel to standing at a child's table, and now we need to progress the task. On a piece of paper, write down five ideas about what you can do to approach the next treatment session from a task-oriented perspective. Save this piece of paper for think-pair-share. Note that not all NIPs are appropriate for these strategies. Patients who do not present with threshold abilities cannot engage successfully and may need compensatory intervention.

Keep reading until you get the page 21, "Motor Learning Strategies". I want you to read through the section with intention. Page 23 gives you a table that outlines all of the things that are written in the narrative pages prior to that page. Take a minute and think about a time when you were in the cognitive, associative, or autonomous stages of learning. For example think about learning how to do joint mobilizations in PTA 220. Initially, when we started to learn that, you had to really slow down and think about where your body should be, what position the patient should be in, how much force you should use, and in which direction. Later, after we practiced a lot, you moved into the associative stage and many of you were able to modify the task slightly depending on your patient or the your goals for treatment. I don't know that anyone is in the autonomous stage yet, but you will be eventually. For your first BAT in this unit, you are going 
to teach something to a couple of your peers. I want you to think about teaching something that will challenge them, and that will also allow them to come through at least one or two of the stages of learning.

Finally, of great import in this chapter is your introduction to neuromuscular facilitation techniques. NDT (Neurodevelopmental Treatment) is mentioned, but in the next unit we will be spending a lot more time on NDT and how it is used for positioning and handling of children with neurological conditions. Right now I want you to focus on just the facilitation and inhibition techniques. There's a Table on page 29, but I have also included a PPT resource for you on Canvas. The PPT is far more comprehensive; please spend some time with it. Facilitation is intended to elicit a response from intrafusal and extrafusal muscle receptors. Inhibition is meant to inhibit or dampen those responses, particularly when they are abnormal or hyper-responsive. When an individual's neuromuscular system is not able to effectively regulate responses and control, facilitation and inhibition applied by a therapist may assist him/her in doing so.

There is some discussion regarding whether there is or is not any carryover from these techniques. Here's my thinking as a neurologically focused PT: If I can inhibit abnormal movement and reflex responses for a brief period of time, and that allows an individual to experience normal movement, then even if there is no direct carry-over of whatever inhibition that I caused with the inhibitory technique, I have still given the nervous system a new experience, a new pattern. That in and of itself is therapeutic, and may allow the nervous system to adapt and change the pattern that it's been stuck with. Ditto for facilitation. If I can facilitate a new motor pattern, then perhaps when I'm done, the patient can reproduce that pattern from a motor memory - one that he or she didn't have before. 


\section{APPENDIX B: Sample iRAT/tRAT}

Unit 2.1 Readiness Assurance Test - D023

Instructions: For the iRAT, please bubble in your answer on the bubble sheet AND select an answer on the actual test. For the tRAT, work with your team to select an answer. Then answer each question by scratching off your answer on the IF-AT form. If you do not find the correct answer, as indicated by an asterisk under the scratch off, reread the question and available answers and select a second answer. Continue until you find the asterisk.

Multiple Choice: (Choose the best answer)

1. While treating a patient who has suffered a CVA, the therapist decides to provide an assistive device for buttoning buttons, so that the patient can dress himself. This is an example of which of the following intervention strategies?
a. Restorative
b. Impairment-based
c. Task-oriented
d. Compensatory

2. Which of the following is related to the task requirements of a therapeutic task?
a. The biomechanical demands inherent in its performance
b. The movement sequence selected by the patient
c. The adaptive equipment required for success
d. The patient's ability to adapt to other environments

3. Which of the following patients is likely to be limited in his ability to dress himself due to a lack of threshold abilities?
a. A patient with an L3 SCI
b. A patient with a CVA and profound UE paralysis
c. A patient with a CVA and limited trunk and pelvic movement
d. A patient with a TBI and resultant emotional lability

4. A therapist who begins working with a patient who has just experienced a CVA and who presents with poor trunk stability, elects to begin treatment at bedside with bed mobility activities. She is likely taking into account:

a. The time required for the CVA to resolve and the bleed to stop

b. The confusion of the patient so early after the CVA event

c. The degrees of freedom problem encountered by neurologically involved patients

d. The patient's need to become reoriented to his body and it's location in space

5. Guided movements during therapy have all of the following rehabilitative benefits, except:

a. The therapist can substitute for missing elements

b. The therapist can ensure safety of the patient and him/herself

c. The patient can focus in controlling fewer body segments 
d. The patient is able to experience tactile and kinesthetic input

6. The stage of learning in which practice should be distributed, the environment should be closed, and intrinsic and extrinsic feedback should be paired, is the:
a. Autonomous Stage
b. Associative Stage
c. Cognitive Stage

7. Walking is an example of what type of activity?
a. Serial
b. Discrete
c. Continuous
d. Complex

8. All of the following are facilitory, except:
a. Prolonged stretch
b. Tapping
c. Joint approximation
d. Joint traction

9. The use of which of the following modalities has proven effectiveness with neurologically involved patients?
a. Ultrasound
b. Heat packs
c. Traction
d. Electrical stimulation

10. A patient's ability to utilize a different motor strategy when task demands change is called:
a. Variation
b. Flexibility
c. Transferability
d. Variability 


\section{APPENDIX C: Sample Basic Application Task (BAT)}

Unit 2 - TBAT 2.2 - Unfolding Case Study

Maddie is a 6-month-old infant whose birth weight was 5 pounds 5 ounces, head circumference was 14 inches, and her length was 18 inches. She presents to the clinic with her parents. She has been referred for a developmental assessment. Maddie was born 7 weeks prematurely. How do you document her chronological and adjusted age? (http://www.marchofdimes.org/baby/thepremature-infant-how-old-is-my-baby.aspx)

\section{1}

Chronological age:

Adjusted age:

You observe Maddie's gross and fine motor development during her visit. She presents with a Moro, Galant and an asymmetric tonic neck reflex. She doesn't support weight on her feet and in ventral suspension, she makes no attempt to extend her head or lower extremities. You conclude that:

\section{2}

A. Persistence of the primitive reflexes for this age is normal

B. The patient is too young for postural reflexes

C. The patient most likely has developmental delay with an upper motor neuron lesion

D. The patient has hypotonia from muscular weakness

Your next patient is a 6-month-old male infant named Teddy, who appears to be developing normally. You decide to assess for a positive Landau reflex. What is seen when the Landau reflex is elicited and when does it appear?

\section{3}

A. In the vertical position, the baby will support weight on his feet. Appears at 3-4 months of age.

B. In ventral suspension, the baby will extend their head and lower extremities. Appears at 4-5 months of age.

C. In the supine position, the baby will extend the arm and leg on the side that the head is turned toward. Integrates at 5-6 months of age.

D. In ventral suspension, when the back is stroked the trunk and hips swing toward the side of the stimulus. Appears at 3-4 months.

E. In the sitting position, the baby will extend the arm and hand to catch himself and prevent falling to one side. Appears at 5-7 months.

1.4

The other reflexes referred to above, in 1.3, are the: 
, and

Teddy has a stable sitting posture when placed in the sitting position and catches himself if he starts to fall. What age is this finding developmentally appropriate for?

\section{5}
A. 4 months
B. 6 months
C. 8 months
D. 10 months

Teddy is also creeping. Which statement is the most correct concerning crawling and creeping?

\section{6}
A. Crawling develops after creeping.
B. Crawling is asymmetric while creeping is symmetric.
C. Creeping is quadruped locomotion on hands and knees.
D. Crawling occurs at 6 months of age.

Teddy's brother and sister are also along on the visit. Teddy's parents ask if they should be concerned about Teddy's older brother, because he has not yet started walking. At what age would you be concerned about an infant that is not walking?

\section{7}
A. 12 months
B. 14 months
C. 16 months
D. 18 months

Meanwhile, Teddy's sister is toddling around the gym, walking with a wide base of support and arms held up high in front of her, above the level of her waist. Which of the following ages is she most likely to be with this gait?

\section{8}
A. 24-months old
B. 30-months old
C. 18-months old
D. 14-months old

You are finishing up with Teddy. You decide to do the Moro reflex test last. Why do you make this decision?

\section{9}

A. The infant's cooperation is best at the end of the examination

B. Infants this age usually resist reflex testing 
C. The parent can take the infant and hold him at the end of the examination.

D. The results are most accurate when done at the end of the examination.

After you are finished with Teddy, you have an opportunity to see a newborn with the physical therapist. Which of the following best describes the normal posture of a newborn in the prone position?

\subsection{0}

A. The arms should be in extension with the legs in flexion.

B. The legs and arms should be in extension.

C. The legs should in extension with the arms in flexion.

D. The legs and arms should be in flexion.

The PT performs several assessments of the newborn. When the PT turns the baby's head gently to the right, the infant extends the arm and leg on the nose side and flexes the arm and leg on the skull side. You know that:

\subsection{1}

A. The baby is demonstrating the ATNR, which is normal for a newborn.

B. The baby is demonstrating the ATNR, which is abnormal for a newborn.

C. The baby is demonstrating the STNR, which is normal for a newborn.

D. The baby is demonstrating the STNR, which is abnormal for a newborn.

What would the PT do if she wanted to elicit the other reflex noted above?

1.12

She would

The PT completes her assessment by evaluating for several reflexes and reactions. Match the following reflexes to the means by which the PT elicits them.

1.13

\section{Column A}

Palmer Grasp

Plantar Grasp

Moro

Sucking

Placing

Babinski

TLR

Rooting

\section{Column B} A.
B. Place the baby in prone and s/he will flex; in supine s/he will extend
C. Lower baby's head rapidly while cradling him/her
D. Place clean object on tongue
E. Apply pressure to palm of hand
F. Apply pressure to sole of foot
G. Stroke sole of foot from heel to toe
H. Lightly stroke cheek near one side of mouth 
1.14

Which of the above reflexes would it be appropriate to assess for in a newborn? Place an asterisk next to those that would be appropriate. 